\title{
EL SUEÑO DE ISAAC Y LA TRANSFORMACIÓN DE LOS SISTEMAS EDUCATIVOS EN LA SOCIEDAD DE LA INFORMACIÓN
}

Resumen: Internet como herramienta educativa y fuente de información ha sido el sueño de muchas generaciones. Ahora que está al alcance de nuestras manos, apenas un porcentaje muy reducido de la población aprovecha su potencial para mejorar su formación. Los Gobiernos de numerosos Estados están haciendo un notable esfuerzo por tratar de adiestrar a las nuevas generaciones en estas tecnologías. Si bien la intención es buena, no siempre se logran los objetivos. En este artículo se analiza y discute la evolución de la implantación de los sistemas educativos que utilizan la Red como recurso de información en la educación y la adquisición de las competencias que nos permitan aprovecharlo a lo largo de la formación necesariamente continua en el mundo digital.

Palabras clave: Internet; innovación educativa; neutralidad de la Red.

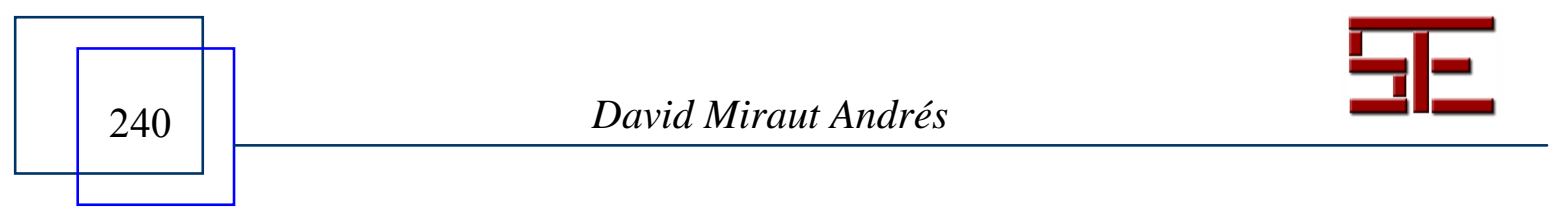




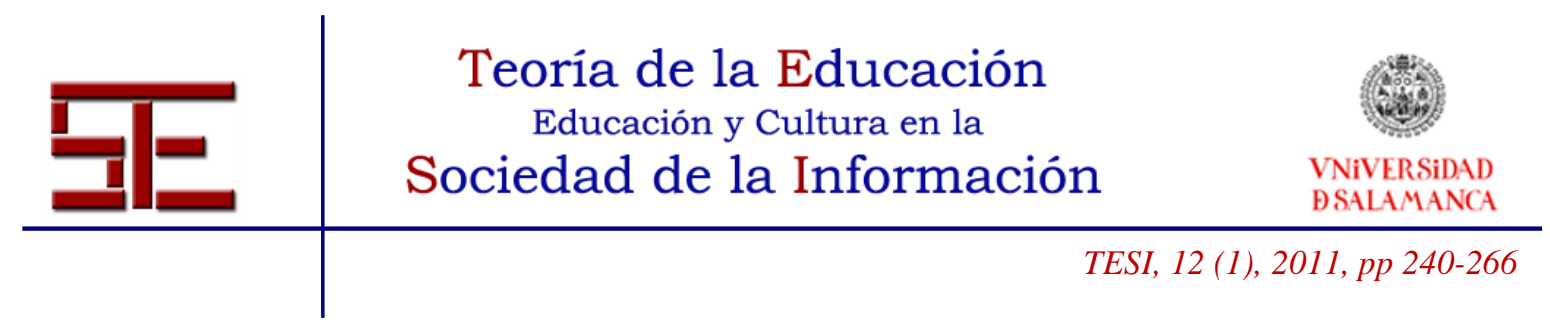

\title{
ISAAC'S DREAM AND THE TRANSFORMATION OF EDUCATION SYSTEMS IN THE INFORMATION SOCIETY
}

\begin{abstract}
Internet, as an educational tool and information source, has been the dream of many generations. Now it is at our fingertips, but only a very small percentage of the population uses its potential to improve their training. Governments of many countries are investing large sums of money to train new generations of these technologies. While the intention is good, goals are not always achieved. This work analyzes and discusses the evolution of the implementation of educational systems that use the Internet as an information resource in education, and the acquisition of skills that allow us to use it throughout a life-long training in the digital world.
\end{abstract}

Keywords: Internet, educational innovation, net neutrality

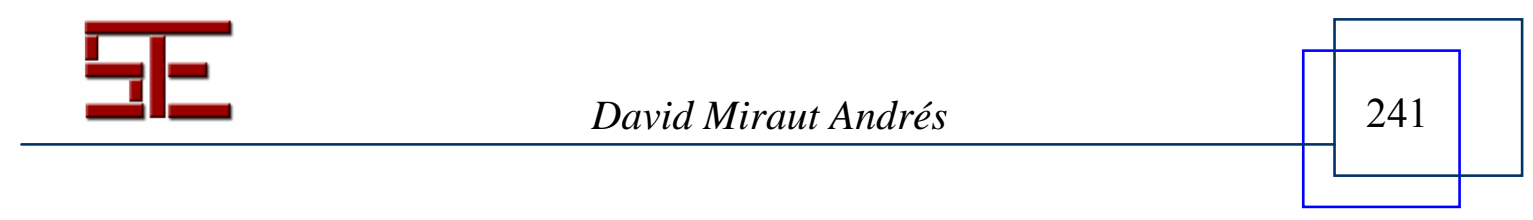




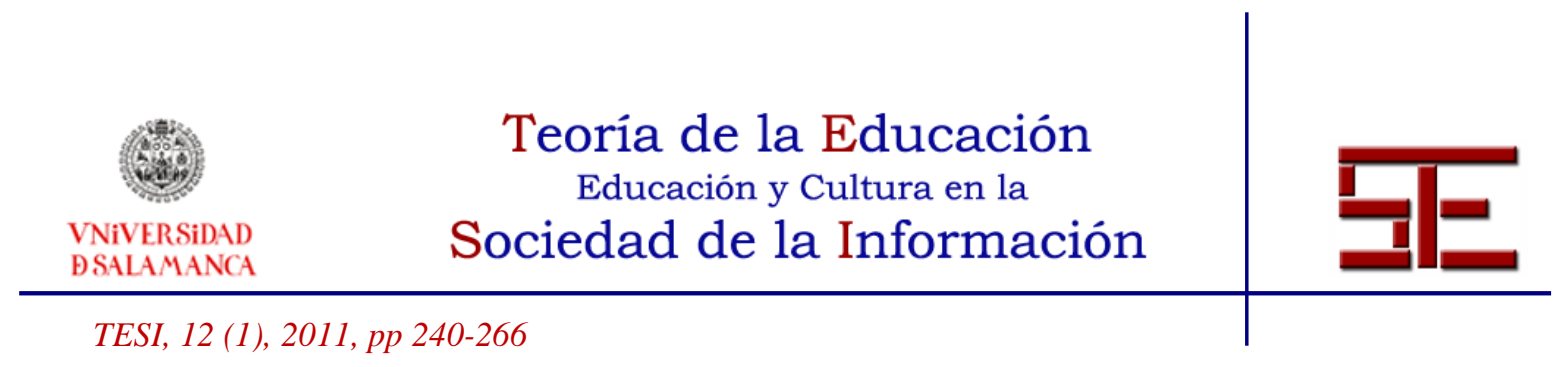

\section{EL SUEÑO DE ISAAC Y LA TRANSFORMACIÓN DE LOS SISTEMAS EDUCATIVOS EN LA SOCIEDAD DE LA INFORMACIÓN}

Fecha de recepción: 20/12/2010; fecha de aceptación: 15/03/2011; fecha de publicación: 31/03/2011

David Miraut Andrés

david.miraut@urjc.es

Universidad Rey Juan Carlos

\section{1.- INTRODUCCIÓN}

Las Tecnologías de la Información y las Comunicaciones (TIC) han tenido un gran impacto en nuestra sociedad. Su adopción ha favorecido la economía de escala en esta industria, reduciendo los costes e impulsando la investigación hasta un punto en el que cada año tenemos productos con mejores prestaciones a precios cada vez más bajos, lo que a su vez ha incrementado su aceptación.

La espiral en la que avanzan las TIC ha beneficiado una situación en la que las soluciones basadas en tecnología nos permiten ser más competitivos en la práctica totalidad de los sectores productivos (Gordon, 2000) y de servicios (McKinsey, 2002). Las TIC han pasado de ser una curiosidad a formar parte del núcleo interno del motor de la industria y uno de los principales factores que le da valor añadido.

Ante estos cambios socioeconómicos, los Gobiernos de todos los países occidentales han visto la necesidad de reforzar los sistemas educativos incluyendo materias relacionadas con las nuevas tecnologías entre las asignaturas clásicas.

Del mismo modo en que los sectores productivos han mejorado notablemente su eficacia con la incorporación de las TIC, cabe pensar que su utilización dentro y fuera de las aulas puede también ayudar a mejorar, no sólo un conjunto de habilidades relacionadas con la informática, sino la propia forma de aprender de nuestros alumnos, su motivación y sus actitudes. Así nuestros jóvenes están creciendo como la primera generación de nativos en un mundo digital -poblado por inmigrantes digitales que han tenido que adaptarse-, y desarrollarán estrategias de pensamiento que les permitan ser competitivos en él (Prensky, 2001).

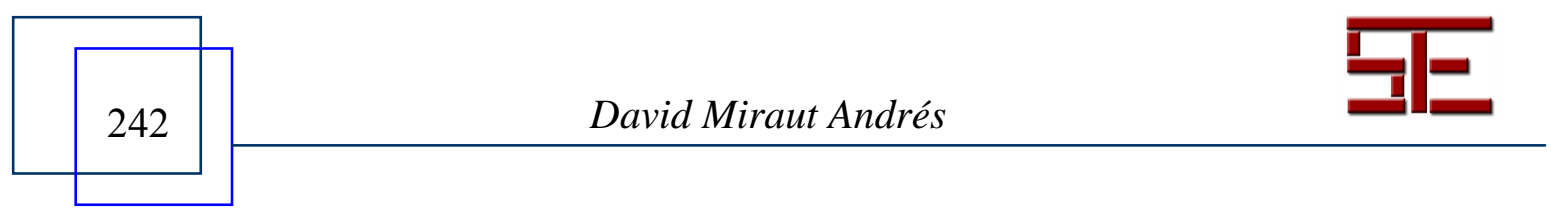




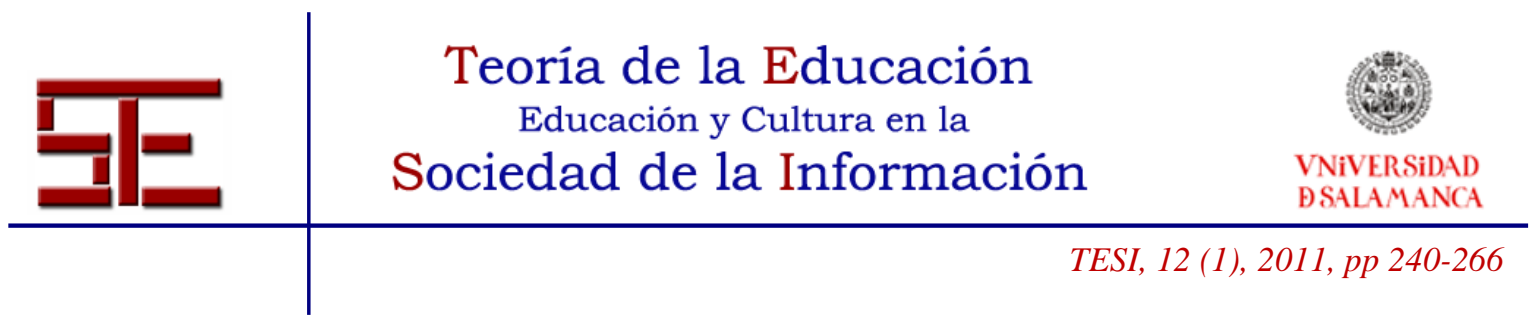

Aprender a aprender se ha convertido en una competencia transversal fundamental en el mundo digital, donde todas las disciplinas que se apoyan en las TIC evolucionan a un ritmo cada vez más rápido.

La actual madurez tecnológica ha derribado muchas de las barreras que hacían del aprendizaje autónomo una utopía. La potencia computacional de los ordenadores actuales y las aplicaciones educativas que la utilizan reducen la dependencia de los alumnos para aprender de un profesor de carne y hueso que les ayude a relacionar conceptos. El acceso a las fuentes de conocimiento ya no requiere un gran desembolso económico, ni siquiera es necesario almacenar la información en medios materialescomo el papel- que ocupan un gran espacio. Es suficiente con tener un ordenador de bajo coste, un conjunto de programas gratuitos (como un navegador) y una conexión a Internet.

La Red de redes se ha convertido en el repositorio del conocimiento de la humanidad, una gran biblioteca de Alejandría accesible por todos desde cualquier lugar. Un sueño hecho realidad y al alcance de cualquiera en los países occidentales.

Paradójicamente, nuestros jóvenes nativos digitales y el resto de nosotros apenas aprovechamos el potencial de estos recursos, ni siquiera se defiende el libre acceso a los mismos, que muchos Gobiernos están mermando de forma más o menos velada.

El presente artículo trata de analizar algunas de las claves de la actual infrautilización de las TIC y la Red como recurso de información en la educación primaria, secundaria y superior. Qué podemos hacer para comunicarnos en el lenguaje de los nativos digitales, cómo espolear su curiosidad en un medio que ya está saturado de estímulos externos, con el objetivo de ayudarles a desarrollar la habilidad de aprender a aprender y utilizar la Red para mejorar su formación.

\section{2.- VISIONES DE UN SISTEMA EDUCATIVO BASADO EN LA RED}

La concepción de la idea de una red con cobertura mundial que pudiese utilizarse para comunicar a los estudiantes con grandes bibliotecas y fuentes de conocimiento se remonta a los escritores de ciencia ficción del siglo XIX.

Julio Verne en una de sus primeras novelas (Verne, 1863), titulada ,Paris en el siglo $X X^{e e}$, describe la capital francesa inmersa en una tecnología difícilmente imaginable en 1863: automóviles con motores de combustión interna, rascacielos, trenes de alta

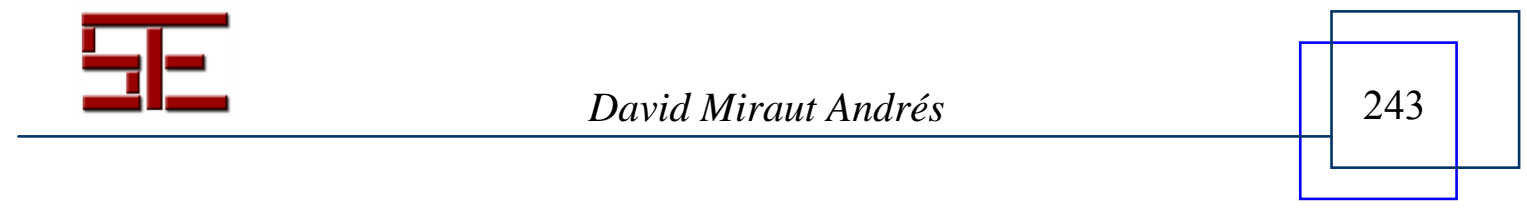




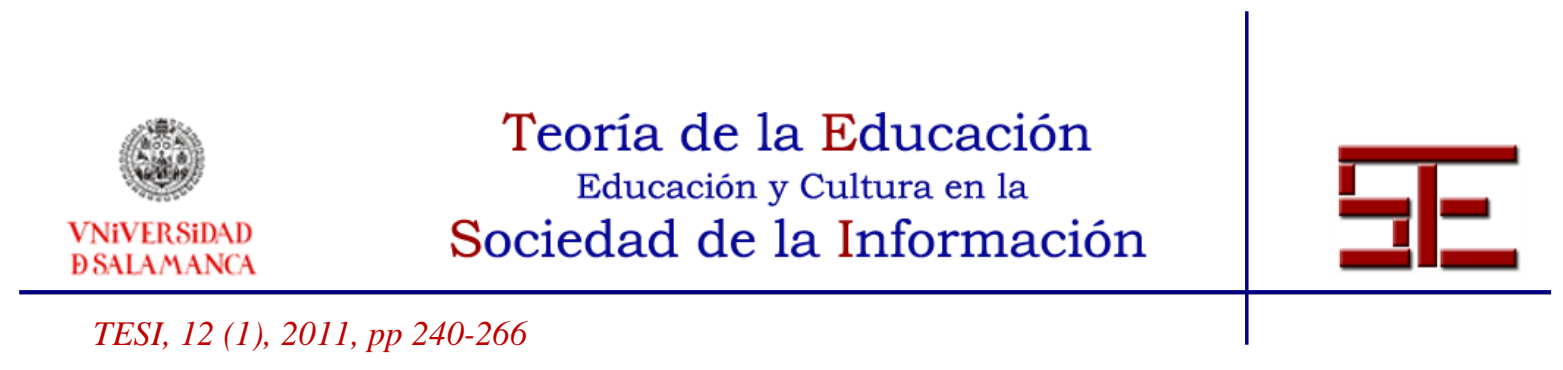

velocidad, ordenadores e incluso una red telegráfica mundial muy similar a nuestra actual Internet.

Una visión preclara y sorprendente de la evolución tecnológica de nuestra sociedad. Demasiado adelantada para su editor, que influido por la perspectiva pesimista de la trama se negó a publicar el manuscrito que no ha visto la luz hasta 1994.

De forma independiente otros autores han desarrollado esta idea en sus obras. En 1938, Herbert George Wells en la colección de ensayos „World Brain“e previó una red global que diese acceso a una Enciclopedia Mundial en la que se ordenase, clarificase y comparase el conjunto de todos los conocimientos de la Humanidad (Wells, 1937). Los estudiantes de cualquier parte del mundo tendrían acceso a copias en forma de microfilms. Así, los estudiantes podrían sentarse con su proyector en su propio estudio para examinar a voluntad cualquier libro, cualquier documento en una reproducción exacta.

La Enciclopedia Mundial se diseñó como una herramienta de paz. Una interpretación común de la realidad evitaría muchos malentendidos que acaban en conflictos económicos y bélicos.

Esta idea fue desarrollada, entre otros, por Arthur C. Clarke. En su libro Profiles of the future (Clarke, 1962), pronosticaba que la construcción del sistema se llevaría a cabo en dos fases, una vez que las dos superpotencias de la época -Estados Unidos y la Unión Soviética- alcanzasen el grado de madurez suficiente para cooperar en lugar de permanecer enfrentadas. Resulta sorprendente como el despliegue de la Red y el acceso a través de terminales de computador ha tenido lugar en las fechas que predijo Clarke en 1962.

Murray Leinster, en su libro „Un lógico llamado Joe’ escrito en 1946, y Martha Green, en su autobiografía „Ozonis - en algún lugar del Universo’ de 1956, también relatan historias en las que aparecen sistemas similares a Internet, en que los usuarios podían comunicarse a través de pantallas que comparten la información instantáneamente a lo largo de todo el planeta.

Todos los autores mencionados se han acercado de forma asombrosa a la idea de Internet y su potencial en la educación de las generaciones futuras. A través de metáforas propias de la tecnología de su época, describen una red que da acceso al conocimiento de forma universal.

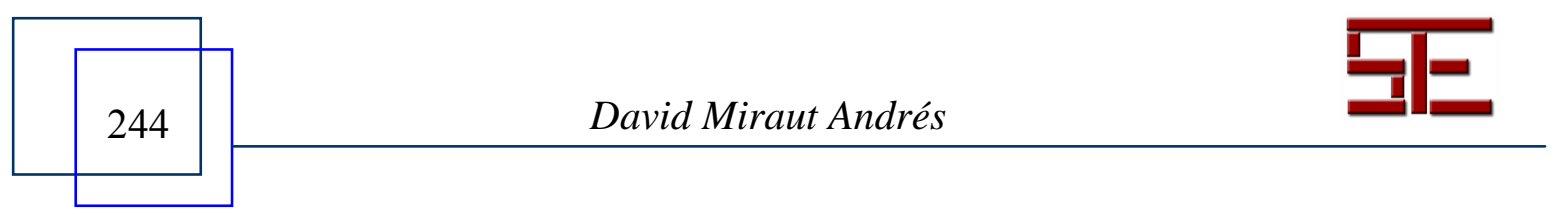




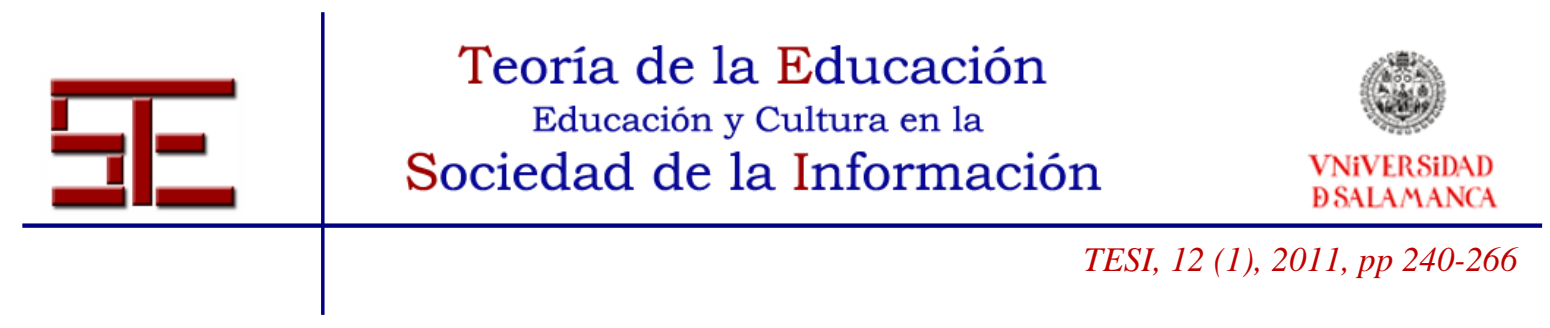

Quizá el escritor de ciencia ficción cuya visión ha descrito con mayor acierto las posibilidades que pone a nuestra disposición la tecnología es Isaac Asimov. Entre los años 1974 y 1980, publicó de una serie de artículos -recopilados en español en el libro (Asimov, 1986) - en los que vislumbraba una nueva concepción del trabajo. Las casas, empresas y bibliotecas estarían conectadas a través de fibra óptica; los trabajadores en sus casas podrían supervisar el trabajo de las máquinas ayudados por una interfaz de pantallas; dicha interfaz también les permitiría acceder a cualquier libro, revista, panfleto o documento para referencias rápidas e imprimirlo para referencias más pausadas; e incluso dar conferencias por circuito cerrado con cada participante sentado tranquilamente en su casa.

En 1988, fue invitado al programa „World of Ideas' de Bill Moyers, donde se dio cita a reputados filósofos, científicos, historiadores, escritores y artistas y se les preguntaba acerca de su punto de vista sobre de nuestra sociedad. La visión expuesta por Asimov tuvo gran calado en las mentes de los norteamericanos, que desde entonces comenzaron a soñar con la noción de una Red abierta como recurso de información en la educación de sus hijos y nietos. A continuación se transcribe la parte de la entrevista (Moyers, 1988):

\footnotetext{
"Asimov: Una vez que tengamos sistemas - de computadoras - en cada hogar cada una de ellas "enganchadas" a enormes bibliotecas donde cualquiera pueda realizar cualquier pregunta y que se le den respuestas; y que se le brinde material de referencia, que sea algo en lo que tú estás interesado en saber desde una temprana edad, más allá de cuán tonto le pueda sonar a otro, eso es lo que a tí te interesa.

y preguntas...

y puedes averiguar...

y haces un seguimiento...

y lo puedes hacer en tu propia casa, a tu velocidad, en tu dirección, ¡a tu propio tiempo!.

En ese entonces, todo el mundo disfrutará el aprender.

Hoy en día, lo que el mundo llama aprendizaje se da a la fuerza. Y todos están forzados a aprender lo mismo el mismo día, a la misma velocidad, en clase. Y todos somos diferentes.

Para algunos va muy rápido, para otros va muy lento, para otros va en una dirección errónea.

Pero démosle una oportunidad, como complemento de la escuela. Yo no hablo de eliminar la escuela, pero sí como complemento de ella. Para seguir sus propios intereses desde el principio.

Entrevistador: Bueno, me encanta esa visión, pero qué pasa con... ¿qué pasa con el argumento de que las máquinas, las computadoras, “deshumanizan” el aprendizaje?

Asimov: Bueno, es que de hecho, la situación es la opuesta.

A mí me parece que a través de estas máquinas, por primera vez, tendremos la posibilidad de disponer de una relación de uno a uno entre la fuente de información y el consumidor de esa información.
}

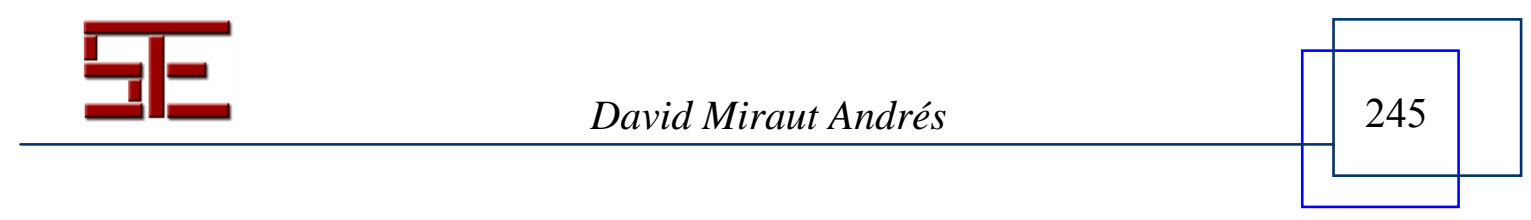




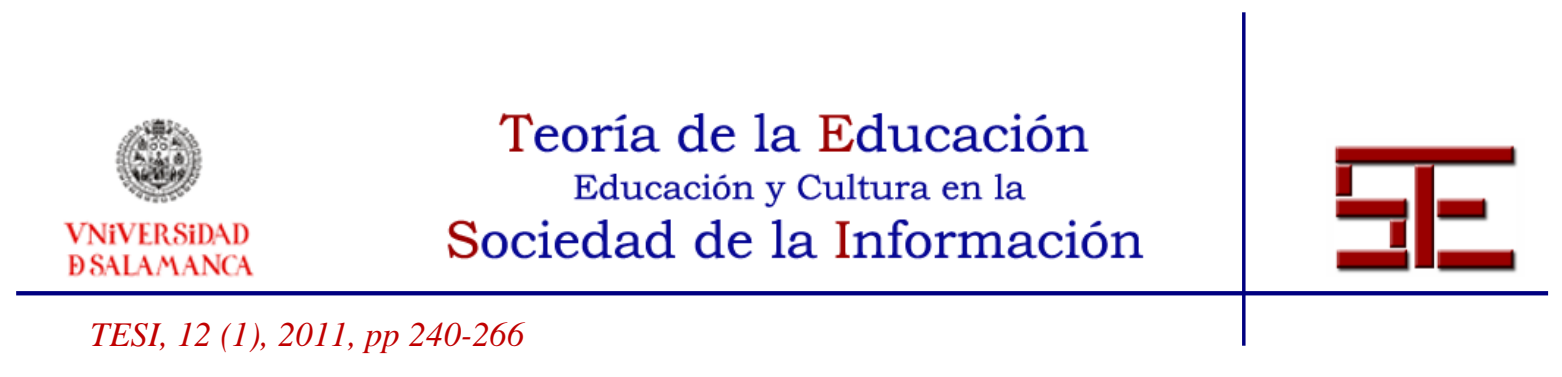

Entrevistador: ¿Qué quiere decir?

Asimov: Bueno, en los viejos tiempos, había tutores para los niños. Una persona que pudiera permitírselo, podía contratar a un pedagogo, un tutor, y él le enseñaría a ese niño el conocimiento de su trabajo, podía adaptar su enseñanza al gusto y las habilidades de los niños. Pero ¿cuántas personas podrían permitirse el contratar a un profesor? La mayoría de los niños eran analfabetos.

Luego llegamos a un punto en el que fue absolutamente necesario educar a todos. La única manera que había para hacer esto era utilizando un sólo profesor para una gran cantidad de estudiantes, y para poder organizar la situación adecuadamente, les dimos un plan de estudios que guiase el aprendizaje.

Entonces... ¿cuántos profesores son buenos haciendo eso? Es como que, en todo lo demás, el número de profesores malos es considerablemente superior a la cantidad de buenos profesores.

Entonces...tenemos una relación de uno a uno para los menos y una relación de uno a muchos para la mayoría.

Ahora, tenemos la posibilidad de una relación de uno a uno para la mayoría.

Todos pueden tener un profesor en la forma de acceso al vasto conocimiento de la especie Humana.

Entrevistador: A través de las bibliotecas que están conectadas a la computadora...

Asimov: Exactamente.

Entrevistador: ¿...en mi escritorio, en mi casa?

Asimov: Correcto.

Entrevistador: Me puedo sentar ahí y "llamar"... bueno... qué pasa si yo sólo quiero aprender sobre béisbol?

Asimov: Bueno, jeso está bien! Aprende todo lo que quieres acerca del béisbol, porque cuanto más aprendas sobre béisbol, más crecerá tu curiosidad por las matemáticas para intentar averiguar qué significan los promedios de carreras y los promedios de bateos, y tal vez entonces te interesarás más en las matemáticas que en el béisbol, si sigues tu propia inclinación, y ¡nadie te lo impone!

Por otro lado, alguien que sí está interesado en las matemáticas, puede de pronto encontrarse entusiasmado por enfrentarse al problema de cómo tirar una bola curva. Y puede encontrarse a si mismo enganchado en la física de los deportes, por ejemplo.

¿Por qué no?

¿Por qué no?

El sueño de Isaac se ha hecho realidad en parte. La madurez tecnológica y el avance de las TIC ponen al alcance de los ciudadanos de los países desarrollados la infraestructura necesaria. La Red de redes y el servicio World Wide Web se han convertido, en sus dos breves décadas de existencia, en el repositorio de conocimiento de la Humanidad.

Gobiernos (Sayare, 2009) y grandes corporaciones -como Google o Microsoft- están digitalizando las principales bibliotecas del mundo (Manuel, 2009) para hacer accesible gratuitamente su contenido a través de Internet. Las principales asociaciones de profesionales junto con las editoriales de revistas científicas también han digitalizado sus archivos para hacer más sencilla su consulta. Proyectos colaborativos -como la

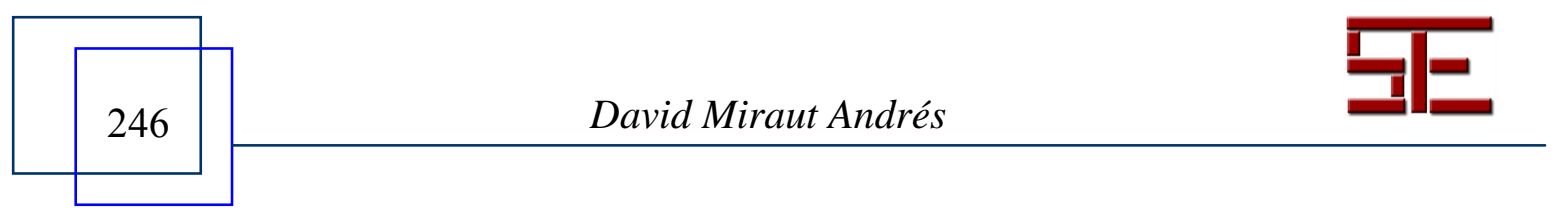




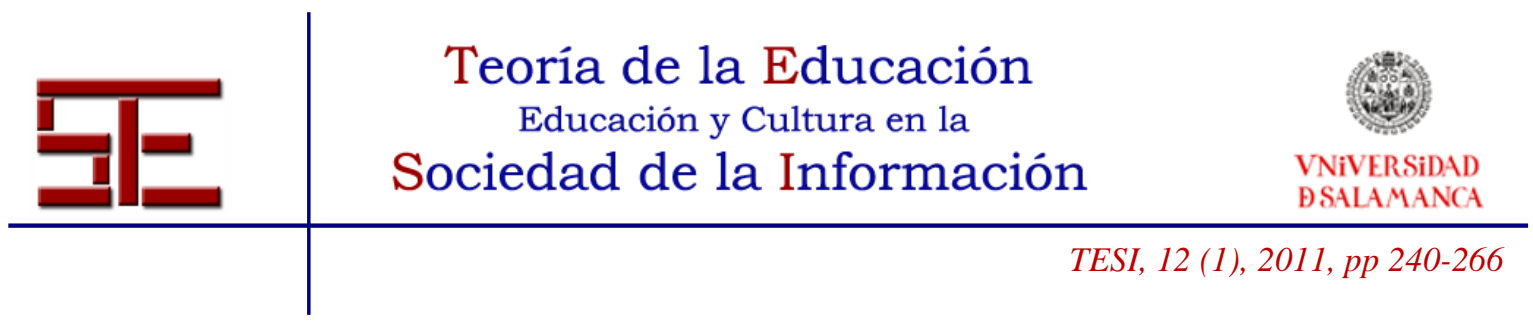

Wikipedia- construyen y revisan la Enciclopedia Mundial de H.G. Wells, con la aportación desinteresada de cientos de miles de individuos. Cualquiera puede escribir un libro o una publicación periódica y darlo a conocer al resto del mundo, las barreras editoriales y los gastos de distribución han desaparecido casi por completo.

La democratización del conocimiento es uno de los pilares fundamentales de la revolución digital.

Sin embargo, el sueño de Isaac no se ha completado. El porcentaje de la población que utiliza eficientemente estos recursos es alarmantemente bajo, incluso entre los nativos digitales.

En la siguiente sección se analizan los esfuerzos de los Gobiernos en educación para invertir esta tendencia, y los factores que rodean la incorporación de las TIC como competencia transversal en el currículum de los futuros profesionales.

\section{3.- RIESGOS Y OPORTUNIDADES DEL APRENDIZAJE A TRAVÉS DE LA RED}

Eurípides decía: "Quienes descuidan la educación de sus jóvenes, condenan a muerte su futuro". Los dirigentes de todos los países, en menor o mayor grado de desarrollo, son perfectamente conscientes de la importancia que tiene para su porvenir la educación tecnológica de sus jóvenes. Parece haber una creencia extendida: si los niños crecen inmersos en la tecnología, que supone una diferencia competitiva en la industria, y aprenden a adaptarse a los cambios que en ella se producen, en el futuro tendremos profesionales que sepan desenvolverse en ella de forma completamente natural.

En este apartado se analizan las oportunidades y los riesgos asociados de la implantación de sistemas educativos "tecnificados" en tres escenarios distintos: las escuelas en países en desarrollo, las escuelas en países occidentales y en la educación universitaria.

\section{1.- Escuelas en países en vías de desarrollo}

En los países en vías de desarrollo, en especial las potencias emergentes -como China, India o Brasil-, hacen un gran esfuerzo por convertir su sociedad y proveer de educación a los jóvenes. Entre la mitad y una cuarta parte del presupuesto público se invierte en alfabetizar y educar a la población en los 25 países más pobres. Desgraciadamente, las grandes diferencias en la distribución de la riqueza dentro de los países favorecen una situación en la que cada vez es más notable la desproporción entre

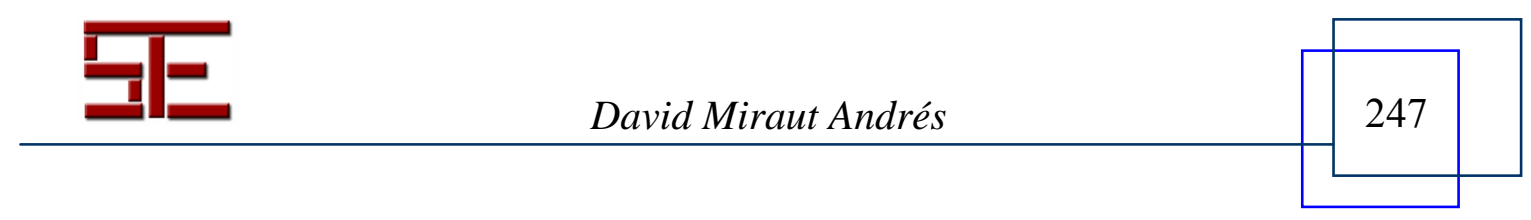




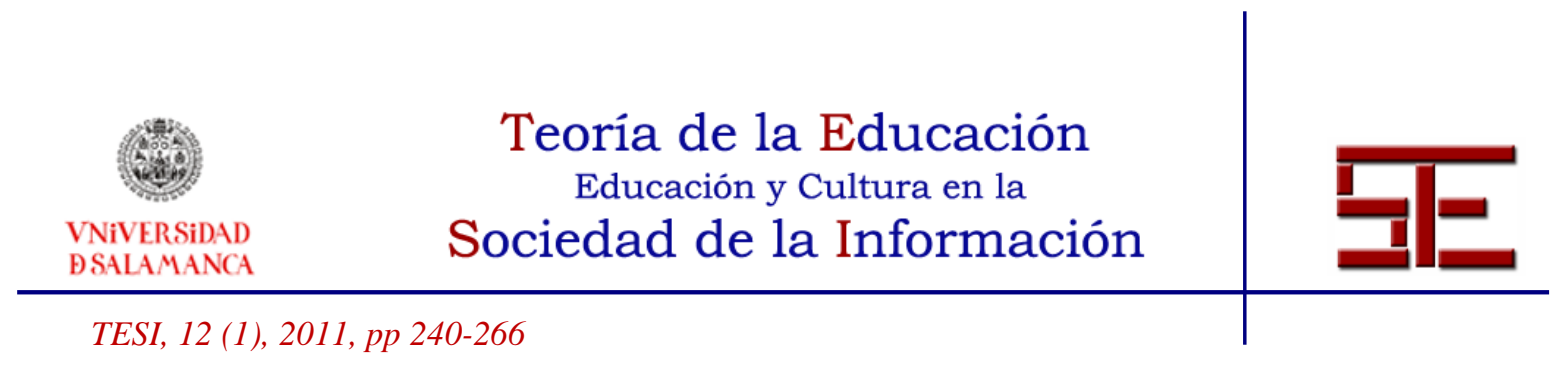

las partidas asignadas a educación y la cantidad de niños y jóvenes que pueden asistir regularmente a la escuela (Moumouni, 1975; Hummel, 1971).

Fieles al proverbio chino "las escuelas de un país son su futuro en miniatura", se han hecho esfuerzos hercúleos en infraestructura para su quebradiza capacidad económica, con el objetivo de mejorar la formación de las nuevas generaciones. Uno de los proyectos más ambiciosos es 'Un portátil por niño' (One Laptop Per Child, OLPC, en inglés) que pretende transformar el panorama de desigualdad actual.

\subsubsection{Un portátil por niño}

El proyecto OLPC fue anunciado en Túnez en noviembre de 2005 por su cofundador Nicolas Negroponte, director del MediaLab del MIT, y alcanzó gran repercusión mediática meses después al presentarse en el Foro Económico Mundial de 2006 en Davos (Suiza) (Perry, 2007).

Probablemente el proyecto educativo sin ánimo de lucro más grande de la década. Su misión original era transformar la educación mediante el desarrollo y distribución de portátiles de bajo coste para cada niño en los países en desarrollo, y el establecimiento de un nuevo modelo de aprendizaje que fomentase la iniciativa e independencia. En palabras de Negroponte (Van der Sande \& Cia, 2008):

OLPC no es, en esencia, un proyecto tecnológico, ni el XO un producto en el sentido convencional de la palabra. OLPC es una organización sin ánimo de lucro que proporciona un medio para un fin. Un fin que ve los niños, incluso en las regiones más remotas del planeta, con la oportunidad de aprovechar su propio potencial, de ser expuestos al mundo de ideas, para que contribuyan a una comunidad mundial más productiva y más sana.

El objetivo era producir y distribuir 100 millones de ordenadores portátiles especialmente diseñados para los niños en edad escolar de los países en desarrollo en un periodo de un par de años y un coste en torno a $100 \$$ por portátil. Un reto extraordinario si consideramos que la producción mundial de ordenadores personales apenas alcanza ese ritmo a nivel mundial, y requiere un coste notablemente superior.

Un gran número de empresas, directa e indirectamente relacionadas con su producción, colaboraron en la concepción del hardware y el software de estos dispositivos.

Los distintos modelos de prototipos que se han ido sucediendo en las demostraciones a la prensa y el modelo que actualmente se comercializa son auténticas maravillas de

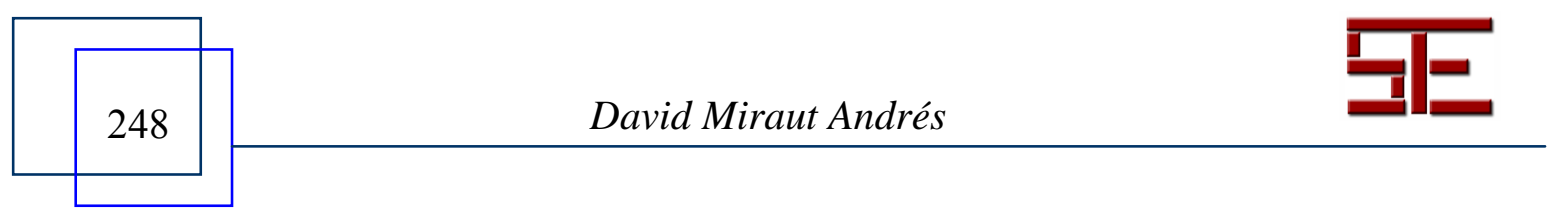




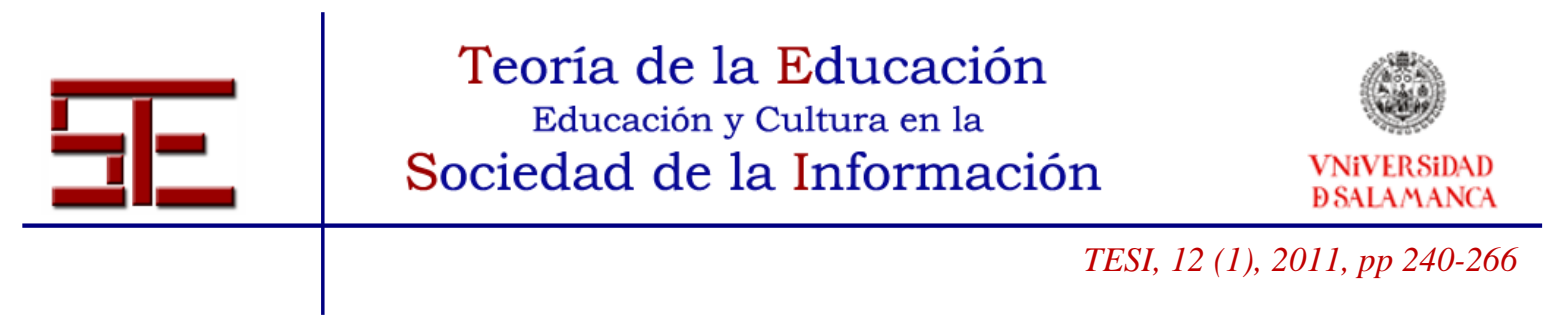

ingeniería capaces de funcionar en entornos tan diversos como los desiertos de Libia o la selva tropical de Brasil. Se ha cuidado especialmente el respeto con el medio ambiente en su diseño, un ejemplo de ello es que su pantalla es la primera del mercado en no tener componentes que requieran mercurio para su construcción.

La pantalla, que funciona en color o blanco y negro, puede girarse para convertir el portátil en un ordenador tipo tablet sin teclado, esta característica -propia de portátiles frágiles de alta gama- es posible en el OLPC ya que la placa base está situada junto a la pantalla, y sólo unos cables tienen que llegar hasta la interfaz del teclado, proporcionando una solución robusta para el tipo de usuarios al que está destinado. La carcasa tiene un grosor de 2 milímetros de plástico duro (casi el doble de un portátil convencional) y al cerrarse queda sellado con un cierre que evita la entrada de agua o polvo. El teclado también se ha fabricado de manera que no pueda penetrar líquido o suciedad en el interior del dispositivo. Su reducido tamaño y la apariencia estética han sido pensados para reducir el posible tráfico de portátiles robados, ya que los adultos que los adquiriesen serían rápidamente localizados.

Se han eliminado casi todas las partes mecánicas, que por movimiento pudiesen desgastarse y reducir la vida útil del portátil: disco duro, ventiladores, generadores eléctricos manuales... Así, dispone de memoria flash para almacenar programas y datos, y un procesador de muy bajo consumo para incrementar el tiempo de uso de la batería más allá del número de horas que los alumnos han de permanecer en clase.

Las redes de distribución de energía eléctrica escasean en las regiones pobres y tienen graves deficiencias, por ello se ha previsto que estos dispositivos puedan recargarse con baterías de $12 \mathrm{~V}$ de coches (que muchas veces hacen de sustitutos de la red en los países en desarrollo) o bien, con microgeneradores de carga manual y alta durabilidad, como el yo-yo a go-go.

Finalmente, los equipos están dotados de antenas WiFi que pueden montarse verticalmente sobre la pantalla para obtener una ganancia de $5 \mathrm{~dB}$ (bastante mejor que las antenas integradas en la mayor parte de los portátiles comerciales). La conectividad inalámbrica es imprescindible para abrir las puertas a los niños a la Red como recurso de información y a las tecnologías de la información como formas modernas de educación. Dado que los puntos de acceso pueden estar muy alejados, los portátiles pueden funcionar como enrutador de una red que dé cobertura a grandes regiones con un consumo inferior a los 350 milivatios. La conectividad con otras máquinas se apoya en un sistema de visualización intuitivo de los entornos local, cercano y lejano, y unas

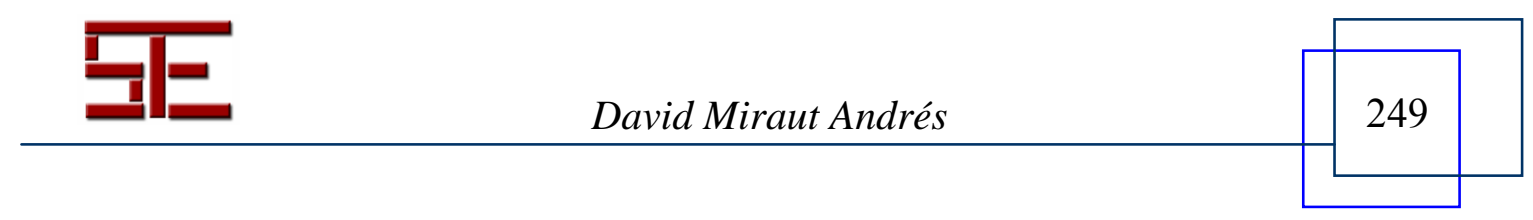




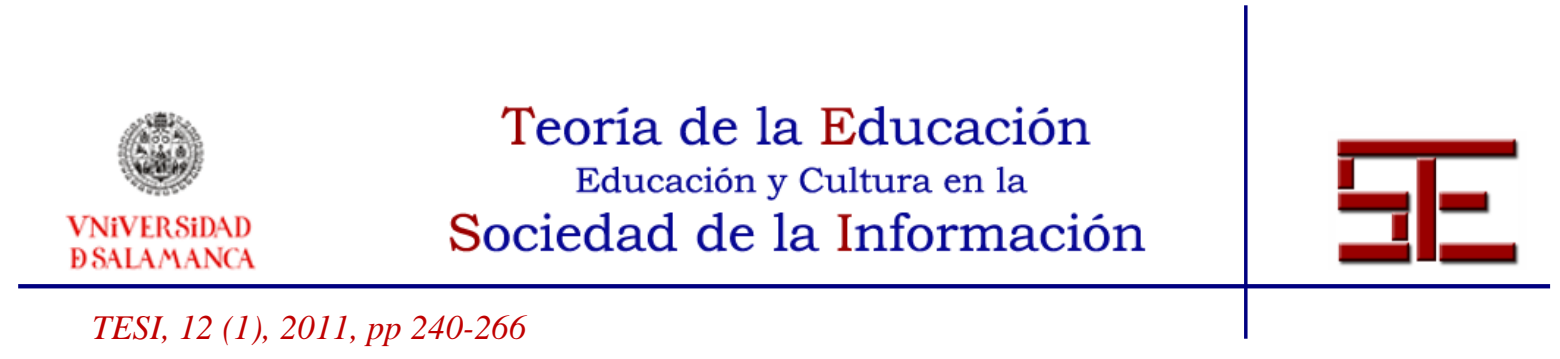

teclas de función ilustradas con símbolos sencillos permiten que los niños puedan establecer las redes.

El sistema operativo está basado en una adaptación de Red Hat Linux con características muy especiales para permitir que los niños experimenten sin miedo a romper o desconfigurar la máquina. Así todos los cambios pueden ser revertidos y volver a un estado en el que la máquina vuelva a funcionar sin problema. El entorno de usuario, llamado „Sugare, no está basado en la metáfora de escritorio a la que solemos estar acostumbrados, sino en la metáfora de un diario. Este paradigma -que tiende a confundir a la mayoría de usuarios adultos acostumbrados a un sistema operativo convencional- ha tenido un gran éxito entre los niños. Mucho más cercana al ambiente del día a día de la escuela y al progreso que realizan en su aprendizaje.

La eliminación de todo hardware superfluo para las necesidades educativas y el volumen de producción hacen que tenga unas características muy atractivas para su precio. Inicialmente pensado sólo para países en vías de desarrollo, el proyecto ha tenido una influencia muy importante en el mercado de hardware a nivel mundial.

\subsection{2 Éxito relativo del proyecto OLPC}

Los proyectos piloto del OLPC en media docena de países en vías de desarrollo resultaron esperanzadores. Aumentó el número de matriculaciones en las escuelas, se redujo el absentismo, mejoró la disciplina y la participación en las clases. Sin embargo, dado que las evaluaciones no fueron llevadas a cabo de forma independiente o sistemática, no se sabe en qué grado la introducción de los portátiles es responsable de estos cambios positivos (Hourcade, 2008). Los problemas relacionados con la falta de formación del profesorado, la deficiente infraestructura para asegurar la conectividad de los dispositivos y la funcionalidad limitada del software empañan estos estudios iniciales.

El coste final de los portátiles se ha visto incrementado por encima del doble de lo previsto: 199\$ [www.laptop.org/en/participate/ways-to-give.shtml]. Un elemento de peso que ha hecho que muchos Gobiernos redujesen drásticamente sus planes de adquisición de portátiles OLPC. Además, la falta de infraestructura para el mantenimiento y soporte de los portátiles en los países donde se va a utilizar, la escasa oferta de software educativo para esta plataforma y la nula adaptación de los contenidos al entorno de los niños son factores que se unen a las dificultades mencionadas anteriormente para su adopción.

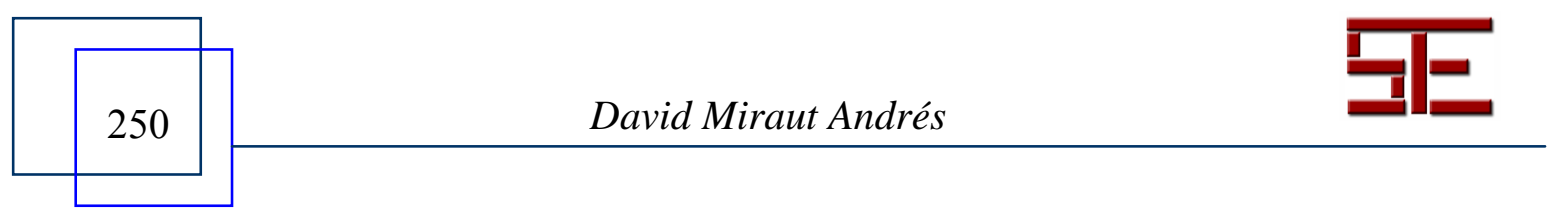




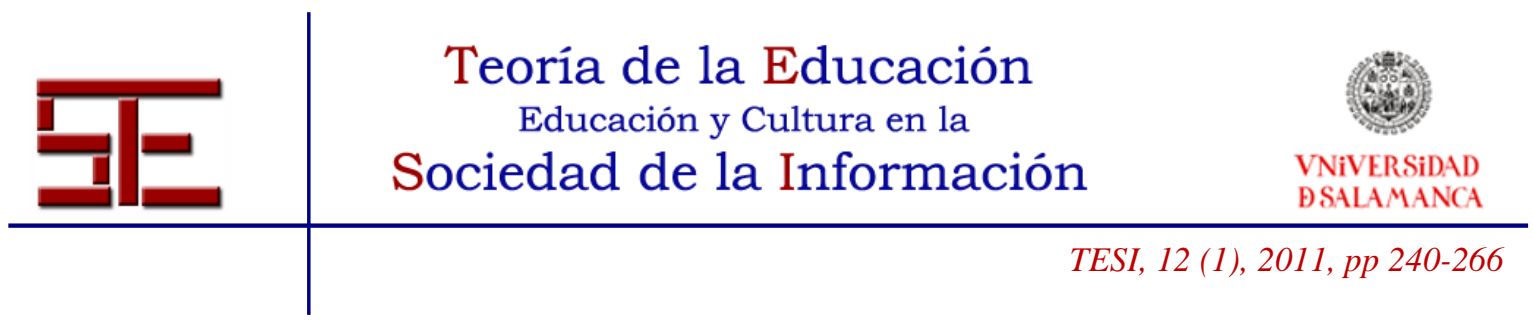

Resulta preocupante la perspectiva de Negroponte en lo relativo a la creación de contenidos y la formación de los profesores, como se desprende de sus declaraciones en la conferencia Digital, Life, Design celebrada en Munich (Alemania) en 2007 (Vota, 2007):

No se trata de formar a profesores. No se trata de construir escuelas. Con todo el debido respeto [haciendo referencia a los esfuerzos de Hewlett-Packard], no se trata de una cuestión de currículum o contenidos. Se trata de sacar adelante a los niños.

La falta de comprensión de las necesidades e intereses de la población no técnica, que finalmente es quien ha de comprar y utilizar los portátiles, ha sido un factor determinante en la limitación del éxito de esta iniciativa.

Por otra parte, la producción de portátiles comenzó mucho más tarde de lo previsto y en el tercer trimestre de 2008 (Kraemer, 2009) sólo se habían manufacturado 370.500 unidades frente a los 5 millones previstos.

Así pues, no es de extrañar que inversiones como la de Nigeria (1 millón de portátiles), Libia (1,2 millones de portátiles) y Brasil (1 millón de portátiles) se hayan evaporado, y que otros países hayan moderado sus pedidos.

\subsubsection{Influencia en el mercado de hardware y el consumo de contenidos en los países occidentales}

Las fuertes restricciones en el coste de los componentes del proyecto OLPC, dejaron a un lado a empresas tan importantes como Intel, Microsoft y Apple, cuyas soluciones no se ajustaban al precio límite de $100 \$$, un precio que en cualquier caso no se ha conseguido alcanzar. Estas empresas también supieron ver el nicho de mercado que mostró Negroponte y han competido con el proyecto OLPC con más de 20 iniciativas distintas (Zuckerman, 2007).

La aparición de estos miniportátiles de bajo coste ha tenido una acogida sin precedentes en los países occidentales. Con una estética más convencional y prestaciones suficientes para la realización de las tareas ofimáticas más comunes, navegación a través de Internet, reproducción de vídeos y música... se ha abierto un nuevo mercado.

A pesar de la crisis, o quizás gracias a ella, muchos usuarios se han comprado un miniportátil cuando en otras circunstancias probablemente no lo hubiesen hecho (o hubiesen elegido uno con diferentes características).

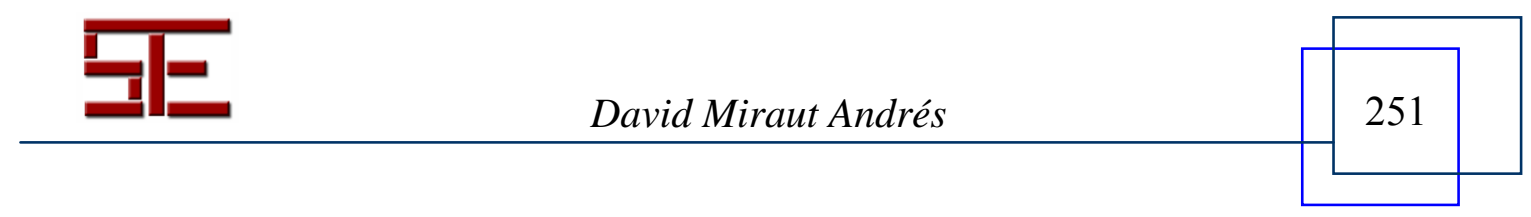




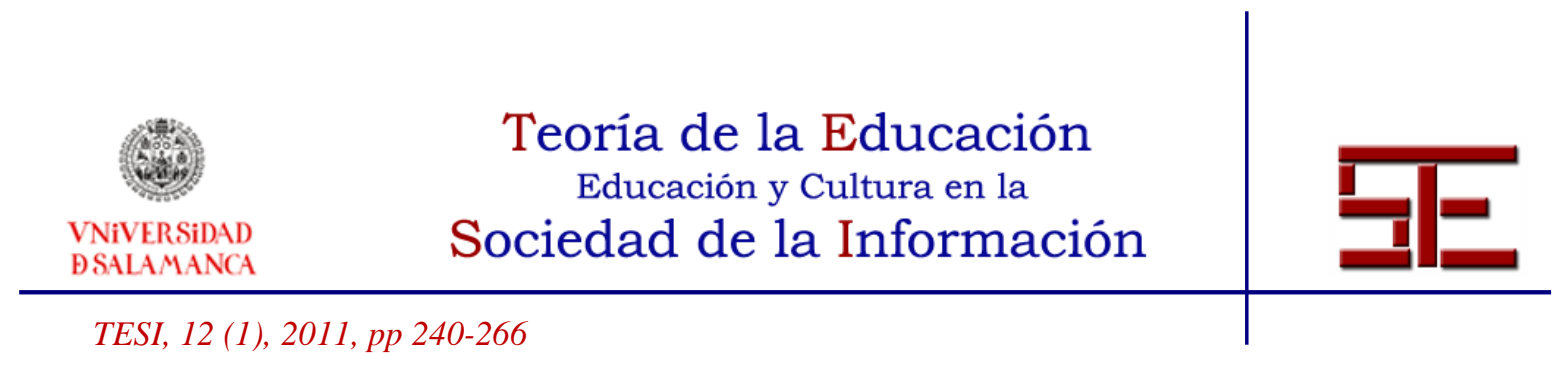

Los portátiles de gama media han mantenido sus precios, al ofrecer mejores componentes a un precio ligeramente superior, y el margen de ganancias de los fabricantes se ha incrementado.

El proyecto OLPC ha demostrado que era posible crear un ordenador de bajo coste con características muy atractivas. Pero lo más importante es el uso y la nueva orientación de estos dispositivos, que en convergencia con los dispositivos móviles, se destinan al consumo de contenidos en lugar de a su creación.

Apple ha llevado con éxito este concepto a dispositivos de alta gama con interfaces innovadoras, como el iPhone, el iPod Touch, iPad... especialmente pensados para personas no necesariamente expertas en informática. Estos dispositivos ofrecen la posibilidad de estar permanentemente conectados a Internet, al igual que los portátiles OLPC, y utilizar la Red como recurso de información y aprendizaje.

\section{2.- Escuelas en países occidentales}

La reducción de los costes de fabricación de los miniportátiles también ha hecho posible su incorporación en escuelas y centros de educación secundaria en los países occidentales.

Los Gobiernos han realizado importantes inversiones en hardware e infraestructuras para los centros de enseñanza, a pesar de que el éxito de los programas piloto ha sido cuando menos discutible. Así, una gran parte de la comunidad -profesores, padres e incluso alumnos- percibe que la forma en la que nos enfrentamos a este desafío tecnológico tiene un mayor componente de marketing que de educación.

En las siguientes secciones se compara la puesta en práctica y los resultados obtenidos en proyectos piloto significativos en países anglófonos y la implantación a gran escala en algunos estados de EEUU, pioneros en este nuevo paradigma de aprendizaje. También se describe el esfuerzo en infraestructuras que está realizando el Ministerio de Educación español y se analizan los posibles obstáculos que podemos encontrar si no aprendemos de las experiencias anteriores.

\subsubsection{Proyectos piloto e implantación en Estados Unidos}

Las tecnologías de la información no son innovaciones aisladas, su valor dependen en gran medida de un ecosistema que incluye hardware, infraestructura de red, software y servicios -como el relativo a la instalación, formación, reparación...-.

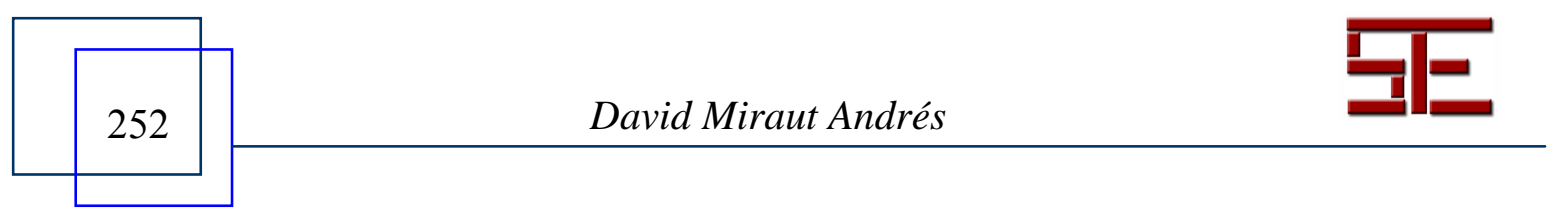




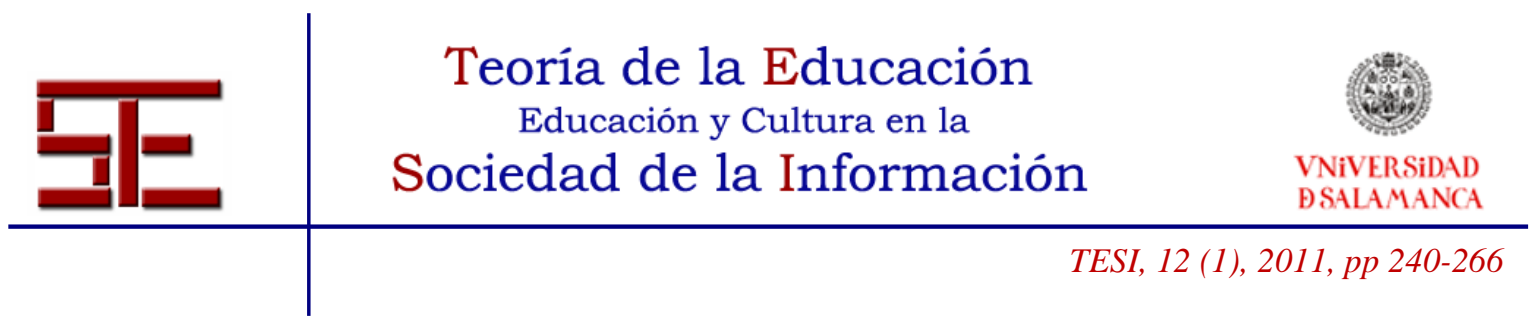

El despliegue de un proyecto educativo que pretenda cambiar la forma en la que entendemos el aprendizaje requiere formar a los profesores, crear software y contenidos digitales adaptados a las necesidades de cada comunidad, dar soporte y servicio de mantenimiento, así como mantener el propósito de consecución del proyecto a largo plazo.

El proyecto OLPC ha sido duramente criticado por la falta de equilibrio entre los agentes de este ecosistema. Resulta muy ingenuo pretender que por el mero hecho de exponer a los jóvenes a la tecnología, estos vayan a aprender sin una guía inicial y una infraestructura que asegure la viabilidad del proyecto durante el tiempo que dura su formación.

En los países occidentales estas dificultades son abordables, especialmente cuando se dispone de apoyo constitucional, pero han de ser previstas con tiempo si se desea que la implantación de estos sistemas se rentabilice proporcionando una mejor formación.

Desde finales de los años 90, con el impulso del fugaz brillo de las empresas puntocom, se han realizado numerosos estudios y pruebas piloto que han dado lugar a ingente cantidad de artículos sobre la integración de las TIC y el uso de portátiles en las aulas de países de habla inglesa. Los alumnos que se embarcaron en esos programas ya han terminado sus estudios, lo que nos da una cierta perspectiva frente a los proyectos que se están iniciando ahora -como es el caso español- y nos pueden ayudar a obtener conclusiones que mejoren la puesta en marcha en esta parte de Europa.

Los resultados han sido tan dispares como el enfoque educativo de cada uno de los centros y la forma en la que han tratado de complementar la falta de visión global de los Gobiernos. En general podemos distinguir dos grandes grupos de acuerdo con los logros obtenidos: el formado por aquellos centros que han conseguido cierto éxito gracias al esfuerzo, preparación e iniciativa por parte de los profesores, y el de aquellos en los que la introducción de estos dispositivos no sólo no ha supuesto mejoras significativas sino que ha supuesto una distracción para los estudiantes. Estos grupos son independientes del estado, distrito o composición étnica de sus estudiantes.

Si bien hay una clara voluntad política para dotar de infraestructuras a los centros educativos, los artículos (Peña-Lopez, 2010) parecen mostrar una falta de previsión del ecosistema descrito anteriormente, al igual que pasó en el proyecto OLPC. Las principales carencias que se apuntan están relacionadas con la inexistencia de un plan

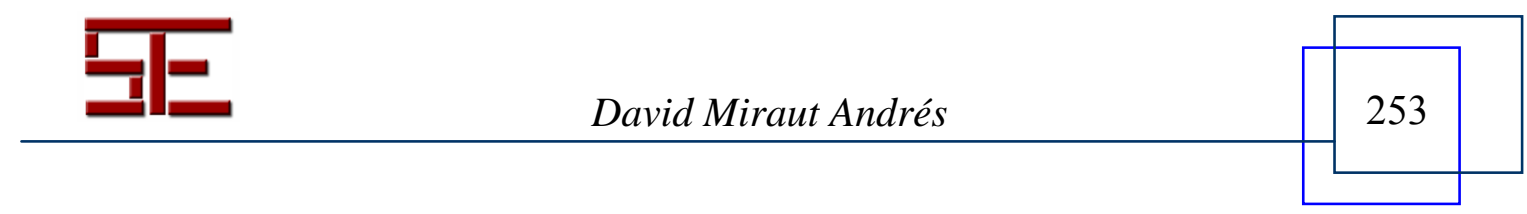




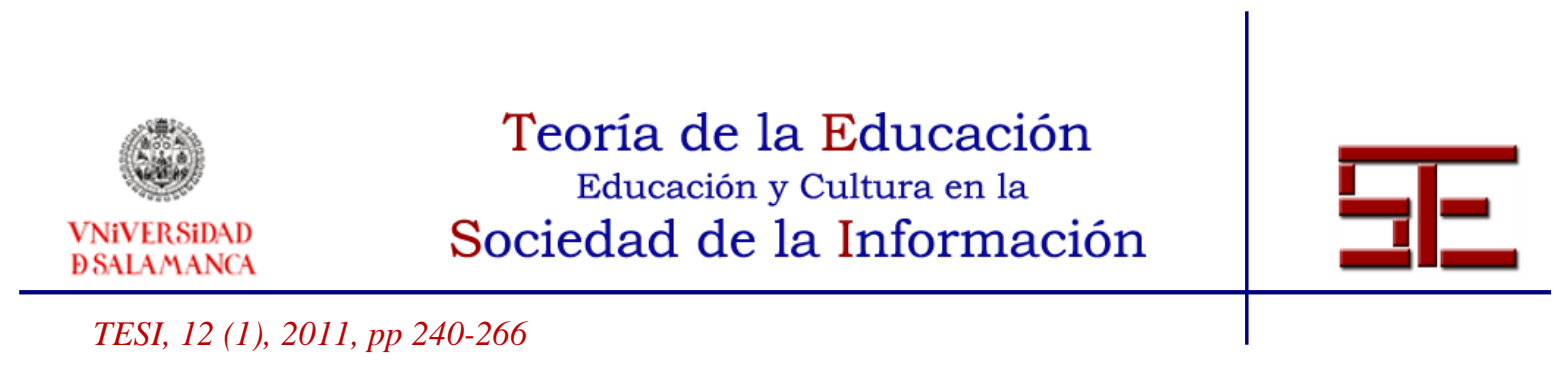

estratégico para la integración de las TIC en las clases -cuya responsabilidad estaba en manos de los departamentos de cada centro-, la inexistencia de programas de formación pedagógica y técnica para los profesores, la falta de programas adaptados a los programas docentes y de comunicación con los padres de los alumnos.

Así, muchos profesores han tenido que invertir más tiempo lidiando con aspectos técnicos externos a la materia que tenían que impartir que en el desarrollo de los materiales para las clases, hasta el punto de volver a los libros y el soporte de la pizarra al no ver ninguna ventaja en el uso de los portátiles.

El estado de Nueva York fue pionero en este tipo de iniciativas, después de acumular una gran cantidad de experiencias en la implantación de portátiles muchos de los centros se están planteando volver a las clases tradicionales, en parte por el esfuerzo que supone y en parte por el alto coste de mantenimiento de los equipos. En una entrevista al New York Times (Hu, 2007), el presidente del consejo de escuelas del distrito de Liverpool, Mark Lawson, declaró: "Tras siete años, literalmente no hay ninguna evidencia de impacto en el rendimiento académico de los estudiantes -ninguna. Los profesores nos dicen que cuando hay una relación uno a uno entre el estudiante y el ordenador, la caja se interpone. Es una distracción para el proceso educativo". Esta opinión es compartida por el estudio realizado en 2007 por el Departamento de Educación de los Estados Unidos (Dinarsky, 2007) en el que se evaluaba a un conjunto de estudiantes que utilizaban software educativo para desarrollar habilidades lingüísticas y matemáticas.

Otros estudios, como el realizado por el Texas Center for Educational Research (Texas Education Agency, 2009), o el presentado en el libro de Mark Warshauer (Warshauer, 2006), profesor de la Universidad de California, tampoco encuentran evidencias significativas de mejora en los exámenes tras la introducción de portátiles en un gran número de escuelas.

Sin embargo, muchos directores y profesores están de acuerdo en que la presencia de los portátiles motiva incluso a los estudiantes más reacios, lo que se traduce en una mayor asistencia y menor abandono en las escuelas.

Cabe destacar que se han dado notables casos de éxito en aquellas escuelas en las que la enseñanza no se limita a la mera transmisión de conocimientos; cuya misión es la de educar de forma integral en valores y ayudar a desarrollar el carácter desde temprana

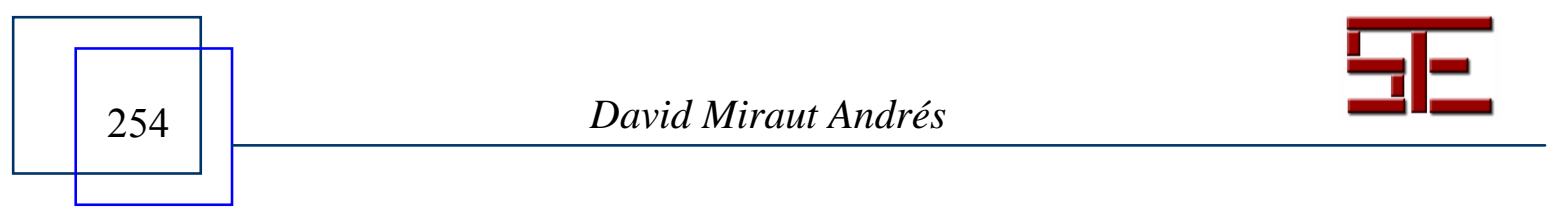




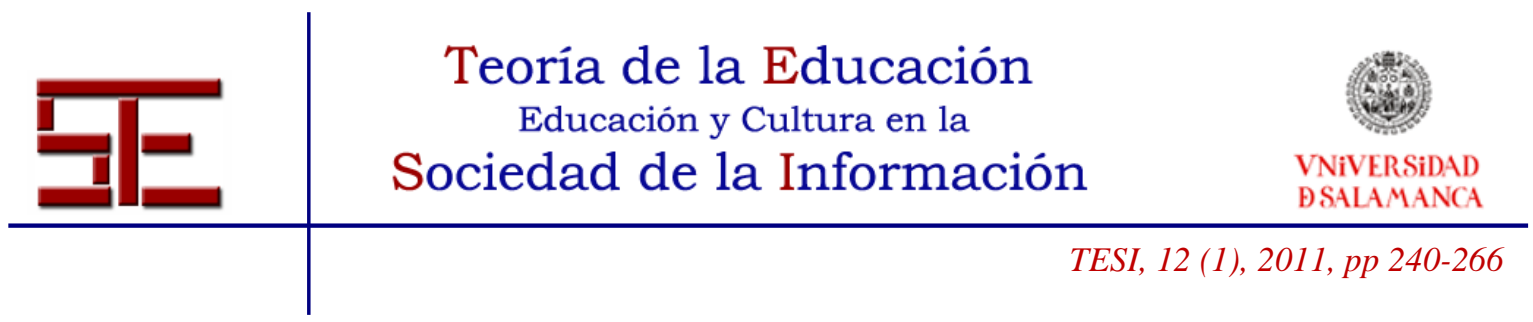

edad (Muir, 2007). Independientemente de la laicidad o confesión de estas escuelas, los profesores han tenido la decisión de paliar las lagunas tecnológicas con esfuerzo y han aprovechado la oportunidad que brindan las TIC para cubrir las necesidades de cada niño de forma personalizada.

\subsubsection{Primeras impresiones de la implantación en España del programa Escuela 2.0}

En septiembre del año 2009, el Consejo de Ministros aprobó el programa Escuela 2.0, que supone una gran inversión por parte del Ministerio de Educación y los Gobiernos de las Comunidades Autónomas para modernizar las instalaciones de los centros educativos con el objetivo de transformar en un periodo de cuatro años las clases tradicionales de $5^{\circ}$ y $6^{\circ}$ de Primaria y $1^{\circ}$ y $2^{\circ}$ de Secundaria.

El programa comenzó ese mismo mes con pruebas piloto en las que han participado más de 7.000 alumnos de diferentes comunidades autónomas (RTVE, 2009), y según una nota de prensa recientemente publicada (Ministerio de Educación, 2010), desde entonces ya se han distribuido 500.000 miniportátiles entre los alumnos, cerca de 100.000 profesores han recibido formación específica en nuevas tecnologías, y se han acondicionado alrededor de 20.000 aulas digitales.

Estas aulas están dotadas con proyectores, pizarras digitales y conexión inalámbrica a Internet. Se espera que los alumnos complementen los medios tradicionales -como el cuaderno- con el uso de los miniportátiles y el profesor guíe la clase también desde un ordenador.

El proyecto Escuela 2.0 se vertebra alrededor de los siguientes elementos:

a) Aulas digitales, dotadas de una infraestructura estándar, y ordenadores portátiles para alumnos y profesores.

b) Conectividad a Internet e interconectividad dentro del aula para todos los equipos, así como facilitar el acceso a Internet desde los domicilios de los alumnos en horarios especiales.

c) Formación del profesorado tanto en los aspectos tecnológicos como en los aspectos metodológicos y sociales de la integración de estos recursos en su práctica docente cotidiana.

d) Implicar a alumnos y a las familias en la adquisición, custodia y uso de estos recursos.

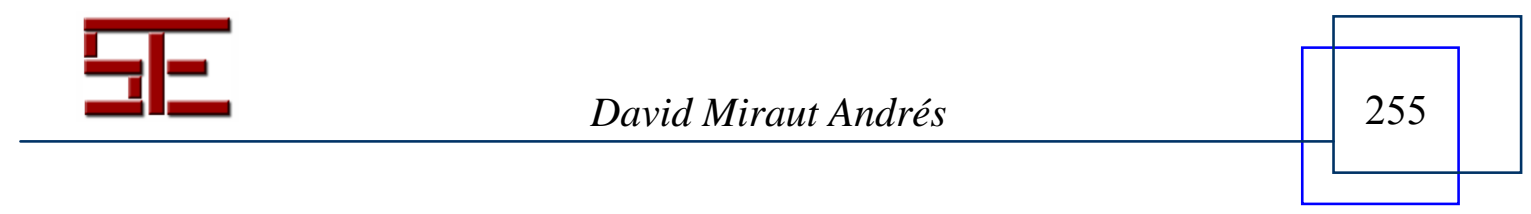




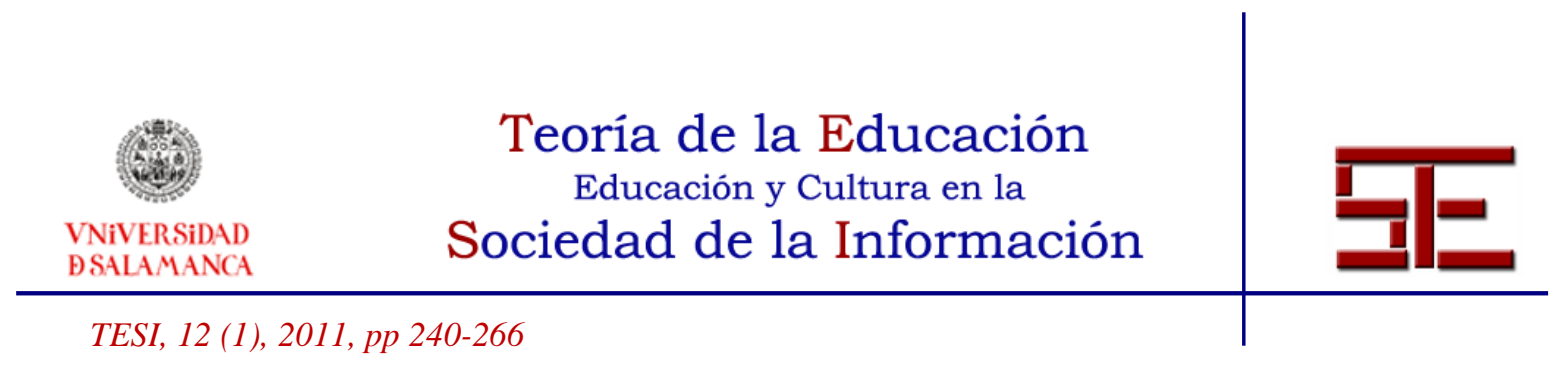

e) Generar y facilitar el acceso a materiales digitales educativos ajustados a los diseños curriculares a profesores, alumnos y familias.

De acuerdo con el Ministerio, la aplicación de las Tecnologías de la Información y la Comunicación a la educación potencia el aprendizaje visual de los alumnos, aumentan su participación, su motivación y su creatividad. Sin embargo, para que esto sea posible -al igual que en el proyecto OLPC y las iniciativas en países anglófonos- se debe cuidar con esmero la creación de los contenidos.

A pesar de ser uno de los elementos principales, este último aspecto no parece haberse contemplado de forma directa en la implantación del programa (Peña-López, 2010). Cada comunidad autónoma tiene libertad para decidir el sistema operativo y el software educativo que se utilizará en los centros. Así, de nuevo parece que el esfuerzo en infraestructura no se ha visto acompañado por una organización centralizada que facilite los contenidos, es más, cada comunidad autónoma tiene su propio portal independiente para el proyecto, sin enlaces a los demás.

Esta falta de unidad ha dejado la responsabilidad de nuevo en manos de los propios docentes, que en estas primeras fases han creado comunidades para compartir los contenidos que crean -como el portal Wikisaber-, han buscado nuevos métodos de participación en clase con los que motivar a los alumnos, y desarrollan materiales para reforzar de forma personalizada la formación de cada alumno. Un trabajo titánico que espera el relevo de las editoriales.

Las editoriales ven el fin de los libros de texto convencionales, pero consideran un gran riesgo la migración de su industria hacia la creación de contenidos digitales para los estudiantes (Carabaña, 2010). La reducción de costes materiales y distribución se equilibra con las inversiones en servidores e infraestructura que dé soporte a la distribución diaria de contenidos. Nuevos modelos de negocio basados en licencias anuales y actualizaciones continuas - que evitan la posibilidad de copia del software y facilitan la monitorización del proceso de aprendizaje de los alumnos- parecen las vías más competitivas a corto plazo.

No basta con digitalizar los libros y poner unos cuestionarios autoevaluados al final de cada tema. Los estudiantes universitarios de hoy en día han pasado menos de 5.000 horas de sus vidas leyendo, frente a las más de 10.000 horas invertidas en jugar a videojuegos (por no mencionar las más de 20.000 horas que han visto de televisión) en

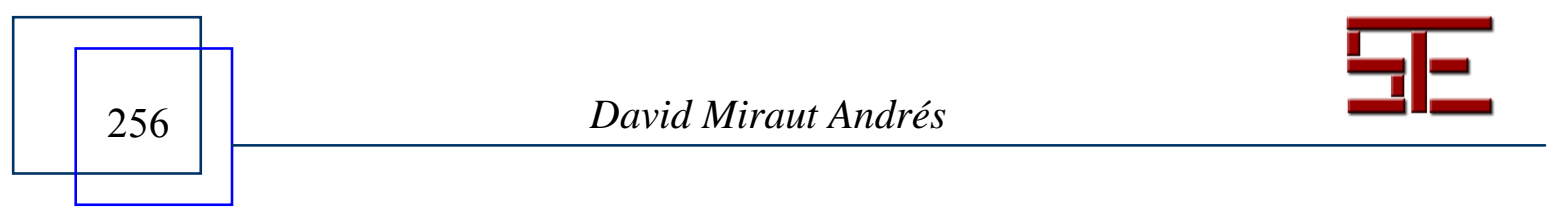




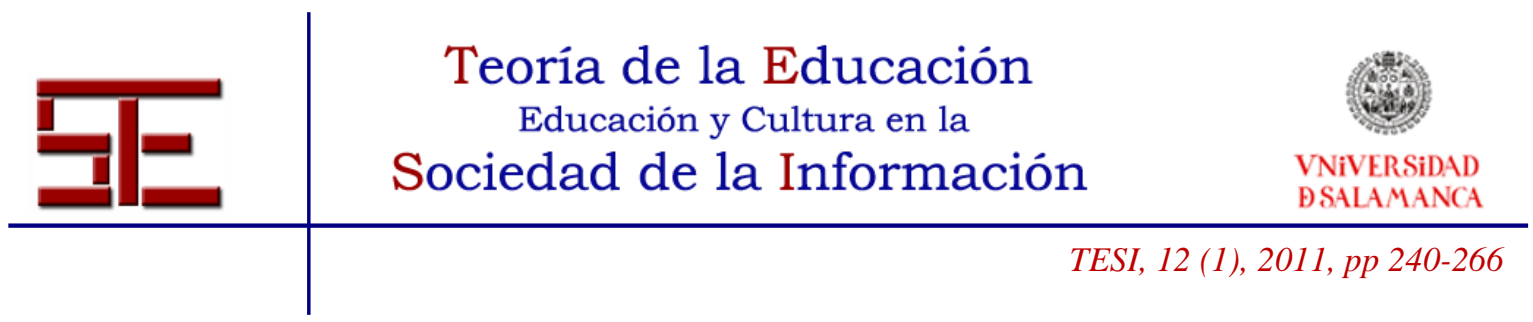

media (Prensky, 2001). La tecnología es parte de sus vidas, pero es necesario orientarlos adecuadamente.

Los programas estadounidenses han demostrado lo que nos dicta el sentido común: no podemos dejar a los niños delante de un ordenador sin más, por muy espabilados que sean. La Red nos ofrece una cantidad inmensa de recursos, pero los niños están sometidos a un ambiente plagado de estímulos y ruido por parte de los medios de comunicación y la propia sociedad que los distrae de su camino de aprendizaje (Hu, 2007), haciendo muy difícil la consecución del sueño de Asimov. Además, Internet no está exenta de peligros que están lejos de ser virtuales.

Por ello, es necesario que en su trayectoria los niños estén acompañados de un adulto, se monitorice su actividad y se adecuen los contenidos al tipo de estímulos en los que están inmersos. Los juegos serios (Marcano, 2008), como Rebeca a través del espejo, utilizan como punto de apoyo aquellas cosas que más les gustan desde una actitud pasiva: las animaciones y los videojuegos, para que pasen a adoptar una actitud creativa que les estimule y les ayude a adquirir nuevas habilidades (Miraut, 2010).

\subsubsection{El informe PISA 2009}

Recientemente se han conocido los resultados del programa de la Organización para la Cooperación y el Desarrollo Económico (OCDE) para la evaluación internacional de estudiantes (Programme for International Student Assessment, PISA), que evalúa los conocimientos de chicos de 15 años de 65 países en áreas clave como la lectura, las matemáticas y las ciencias (Instituto de Evaluación, 2010). Se intenta tener una muestra representativa de estudiantes de cada país para comparar las habilidades que proporciona cada sistema educativo.

España sigue sin alcanzar la media de los países desarrollados según este informe. Aunque la distancia que separa a España de la media de la OCDE y de países como Estados Unidos o Francia es estadísticamente muy pequeña, lo cierto es que ninguno de estos países destaca especialmente. La inversión en educación e integración de las TIC en los países occidentales no parece corresponderse con un mejor rendimiento académico en este nivel educativo.

La gran sorpresa han sido las provincias de China (Mervis, 2010), país que por primera vez participa en el estudio. En especial, la provincia de Shanghái. Con escuelas dotadas

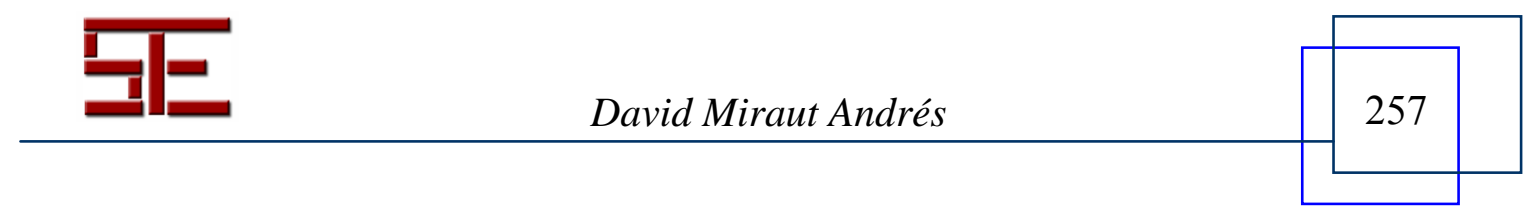




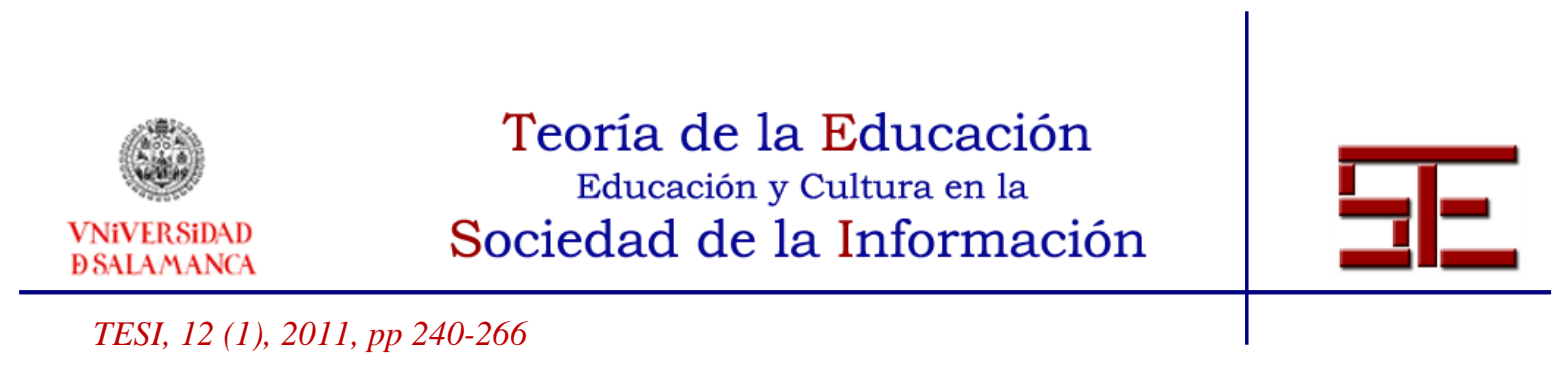

de aulas austeras -apenas unas mesas, sillas y una pizarra-, clases con 45 alumnos por maestro, y un humilde presupuesto (Fernández-Villaverde, 2010), ha conseguido alcanzar la nota media más alta del estudio. Muy por encima de los siguientes países, también asiáticos.

Por ejemplo, en matemáticas, el $26^{\text {ec }} 6 \%$ de los estudiantes de Shanghái tienen calificación de nivel 6 (el más alto en el estudio), frente a un $1 \% 3 \%$ en España ó un $1{ }^{\text {ee }} 9 \%$ en los Estados Unidos.

Los alumnos en esta provincia tienen un horario lectivo semejante al del trabajo de sus padres, entran en las escuelas a las 8 de la mañana y salen a las 5 de la tarde, hora a partir de la cual la mayor parte de los niños practican actividades extracurriculares: idiomas, danza, Go, piano... con las que se llegan a sumar 12 horas de estudio en el colegio al que se suma después el tiempo para realizar los deberes en casa. (FernándezVillaverde, 2010).

La sociedad china es consciente del la importancia de la educación para su futuro. Lejos de desalentar a los niños, estimula su esfuerzo y dedicación. A diferencia de lo que parece ocurrir en algunos países occidentales.

\subsubsection{La informática más allá de los ordenadores}

Tal como ha demostrado el informe PISA, la innovación educativa y el rendimiento académico no dependen de tener más o menos medios materiales. Sino de transmitir la pasión por aprender y la voluntad de superación. La necesidad es la madre del ingenio, la crisis es una oportunidad para utilizar la imaginación de modo que nuestros estudiantes aprendan a aprender.

Los alumnos de las escuelas de Shanghái no tienen tiempo para jugar a la consola o ver la televisión entre semana, y no lo consideran una privación de libertad. En su lugar se consideran afortunados por aprender idiomas, memorizar poemas y jugar al Go (que potencia sus habilidades analíticas). Cuando estos niños - que han crecido en un mundo analógico- crezcan y tengan la oportunidad de acceder al mundo digital, tendrán una base sólida y estarán preparados para aprovechar y disfrutar de la experiencia.

Las habilidades informáticas van mucho más allá de saber teclear, utilizar un sistema de ventanas o navegar por internet. Es algo más profundo y no siempre está directamente ligado a la tecnología como tal. Se trata de un conjunto de estrategias de pensamiento

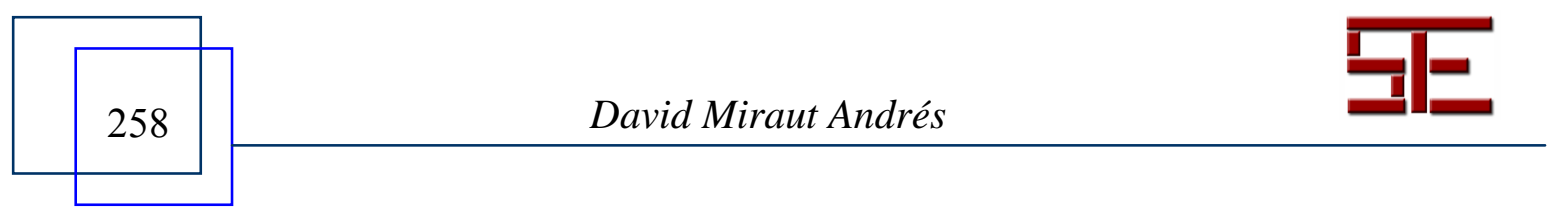




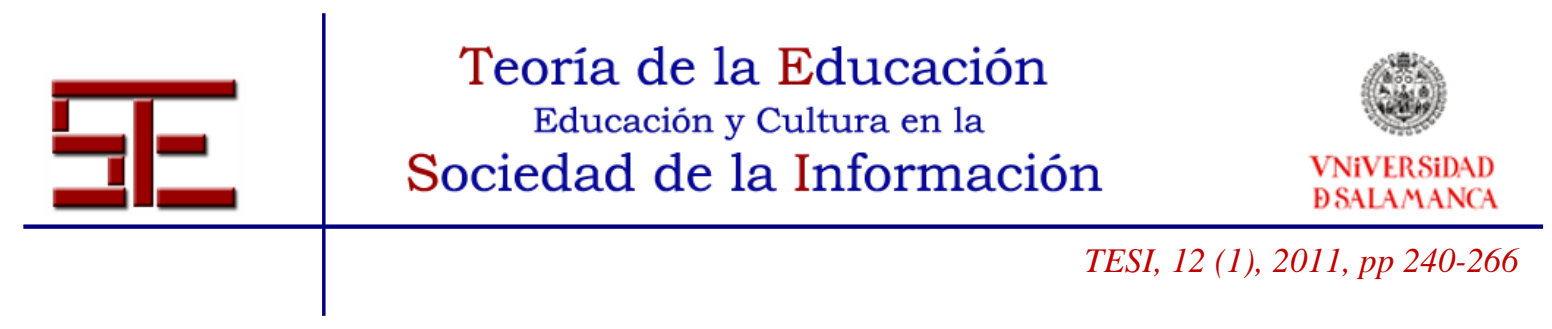

que pueden aplicarse a todas las ramas de la ingeniería, e incluso a la vida diaria, para resolver problemas algorítmicamente de forma eficaz. Estas habilidades se pueden enseñar sin necesidad de encender un ordenador o ejecutar un programa, tal y como han demostrado los investigadores de la Carnegie Mellon (Henderson, 2008). Pero nuestros políticos siguen deslumbrados por la falsa creencia de que la mera exposición a la tecnología hará a nuestros jóvenes más competentes (Pedro, 2009), sin darse cuenta de que la revolución en las aulas pasa por una formación innovadora y constante en los propios profesores.

\section{3.- Educación superior y desarrollo de competencias transversales}

El proceso de convergencia hacia el Espacio Europeo de Enseñanza Superior (EEES) en el territorio nacional ha supuesto un profundo cambio en la estructura y las metodologías de enseñanza en la educación universitaria. Este cambio no se ha visto acompañado de la fuerte inversión en educación necesaria para llevarlo a cabo debido a la política de contención presupuestaria en el sector público español; muy diferente a la aplicada en otros países, como Alemania o Francia, donde se ha procurado reforzar la formación de nuestros profesionales, de los que depende el futuro a medio plazo.

Como consecuencia, las Universidades públicas españolas han tenido que afrontar el reto de la adopción del espíritu de Bolonia con un conjunto de recursos insuficientes. Dos de las principales dificultades se reflejan en el tamaño de los grupos, mucho más grandes de lo esperado, y la mayor dedicación del profesorado en seguimiento personalizado y evaluación continua de los alumnos, que ha visto reducido el tiempo que pueden dedicar a investigación.

La Informática al igual que las Matemáticas, son consideradas parte de la formación de base de muchas titulaciones, a veces como competencias específicas y otras veces como parte de las competencias transversales. Tradicionalmente, en las titulaciones técnicas la atención se ha centrado en las competencias específicas y ha obviado la preocupación por la instauración de ciertas competencias transversales, que ahora son consideradas como uno de los objetivos básicos en los planes de estudio de Bolonia. Las competencias transversales rebasan los límites de una disciplina. Su carácter genérico hace que sean habilidades necesarias para ejercer eficazmente cualquier profesión, y se relacionan con la puesta en práctica integrada de aptitudes, rasgos de personalidad, conocimientos y valores adquiridos. Por ello -antes del EEES- no era frecuente que se considerasen en el plan de estudios de forma explícita en una asignatura determinada.

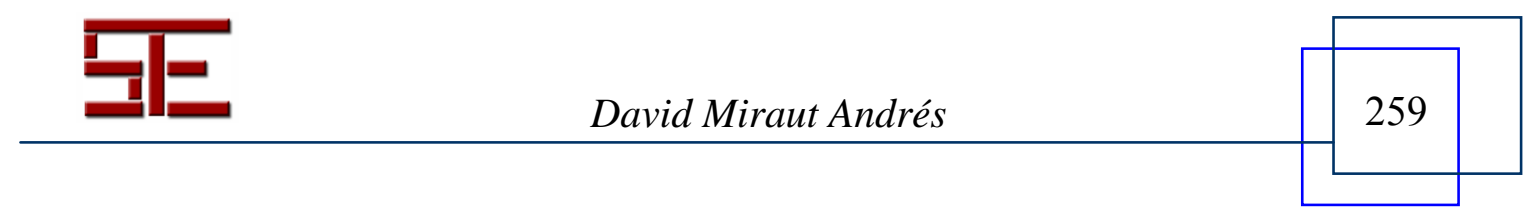




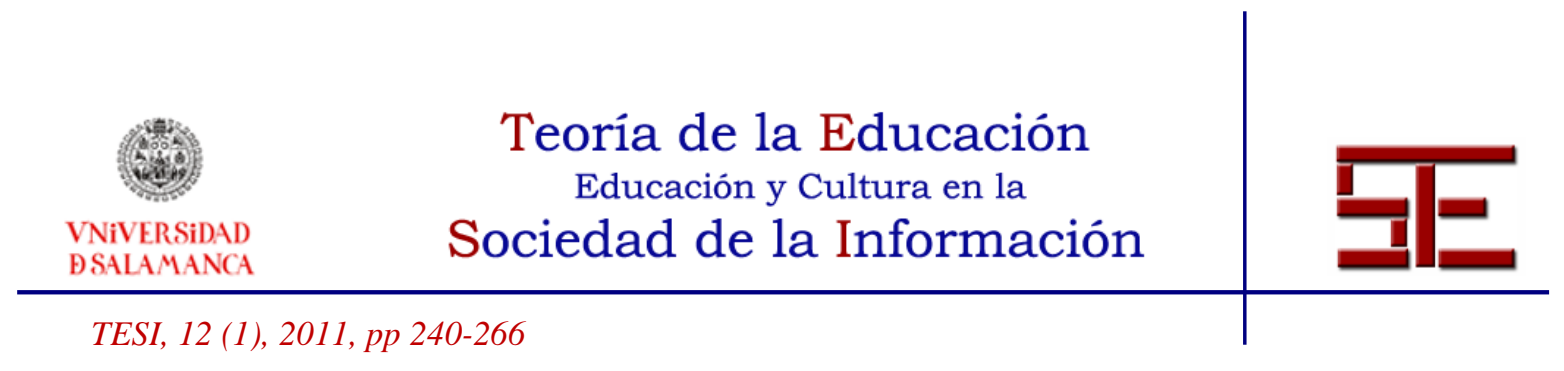

Debido a la dificultad de integrarlas y evaluarlas en las asignaturas por separado, son las más vulnerables en esta situación de crisis económica.

La adopción de las TIC en la vida diaria de la Universidad está mucho más arraigada, tanto en estudiantes como en profesores e investigadores. Las instituciones son conscientes de la mejora de productividad en este estadio educativo, proporcionan los recursos materiales, formación y software para su aprovechamiento. La madurez y motivación de los alumnos es notablemente mayor.

Sin embargo, a pesar de carecer de los obstáculos de los casos expuestos anteriormente, su aplicación en las clases presenciales es limitada y muy desigual dentro de las Escuelas y Facultades del territorio nacional. No cabe duda de que las TIC tienen tantos o más beneficios que en enseñanza primaria y secundaria, pero su adopción en las clases más allá de la proyección de transparencias requiere un esfuerzo importante por parte de los docentes, que ya ven limitada su dedicación a la investigación con la creación y puesta en marcha de los nuevos planes de estudios.

Las TIC abren posibilidades insospechadas hasta ahora. Cuando Google sacó a la luz su servicio GoogleVideo, procuró introducir contenidos interesantes con los que tener la posibilidad de competir con YouTube - que más adelante acabaría adquiriendo-, entre los canales que promocionaba se encontraba GoogleTechTalk, AtGoogleTalks y google Developers, en los que se ofrecen vídeos de conferencias de profesionales y profesores de universidad de prestigio en las que se cuentan de forma accesible temas de lo más diverso relacionados con la tecnología y las humanidades.

Siguiendo su estela, grandes Universidades, como Stanford, MIT ó Berkeley ofrecen ahora de forma gratuita las grabaciones de clases y conferencias impartidas por algunos de los principales expertos en esos temas, a través de portales como videolectures o YouTube.

Las grabaciones en video no son más que una digitalización directa de los contenidos que se dan en las clases, no aprovechan todas las posibilidades que nos ofrecen las TIC, pero son un paso muy importante en el acceso libre al conocimiento, y el sueño descrito por Asimov. Una iniciativa más que encomiable que pone a disposición de todo el mundo las disciplinas e ideas que se enseñan en estas instituciones.

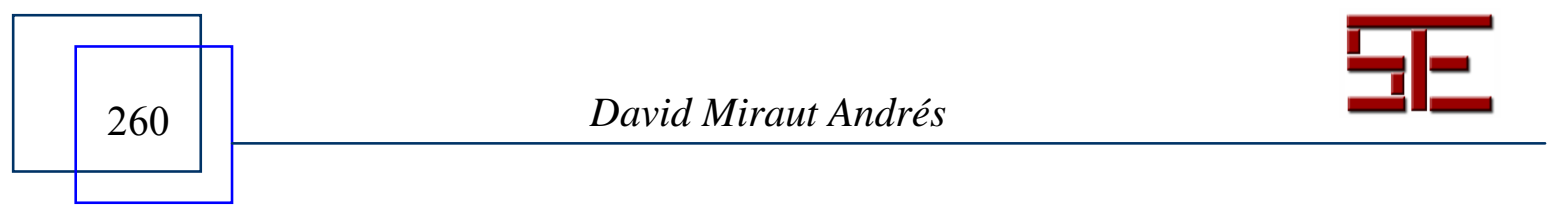




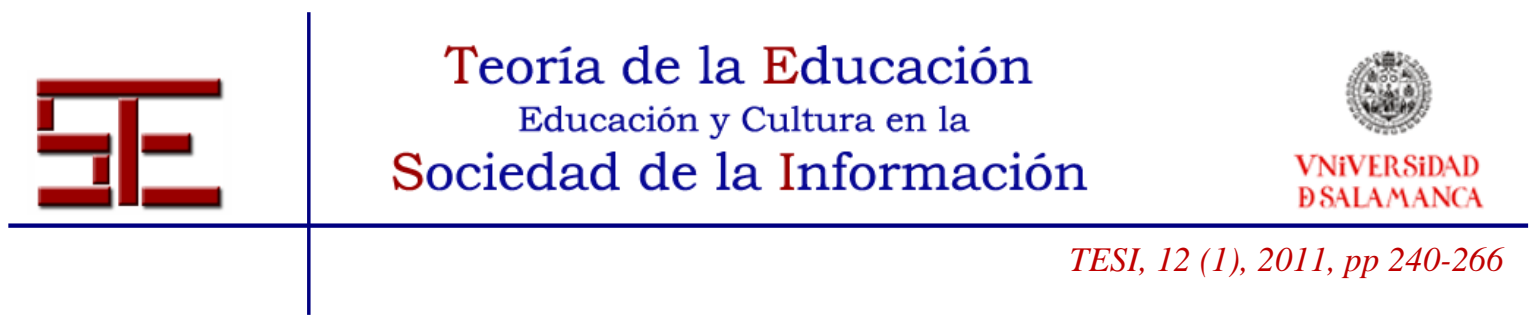

\section{4.- LA FRAGILIDAD DE LA NEUTRALIDAD DE LA RED}

El libre acceso a la información educativa en la Red depende del respeto por parte de los gobiernos y los proveedores de servicios de internet del llamado principio de neutralidad de la red (Wu, 2003).

El principio establece que si un usuario paga por un determinado nivel de acceso a Internet, y otro usuario paga por el mismo nivel de acceso, ambos usuarios deberían poder conectarse entre sí a nivel de acceso contratado. Por tanto, no deberían existir restricciones por parte de los gobiernos y los proveedores de servicios en función de los contenidos, plataformas o sitios web.

El concepto de la neutralidad de la red se remonta a la misma época en la que Julio Verne describió por primera vez un futuro con una red mundial. En la ley federal estadounidense de 1860 se recoge (Central Pacific Railroad Photographic History Museum, 1860):

...mensajes recibidos de cualquier persona, empresa o corporación, o procedente de cualquier línea telegráfica conectada con esta línea en cualquiera de sus términos, será transmitida imparcialmente en el orden de su recepción, sólo los despachos del gobierno tendrán prioridad...

Recientemente, los proveedores de servicios de internet han comenzado a posicionarse en el mercado de los contenidos. Su posición privilegiada, como intermediarios de la información entre las fuentes y los consumidores, puede tentarles a imponer un modelo de servicios diferenciados con el objetivo de controlar la comunicación y eliminar a la competencia. Por ejemplo, penalizando el tráfico hacia determinados sitios web para forzar a sus subscriptores a contratar o utilizar los servicios que al proveedor le interesa.

Esta situación ha generado un intenso debate, ya que -a fecha de la redacción de este artículo- no existe una legislación clara a este respecto en España, y la ruptura de este principio puede suponer un serio detrimento de las libertades y la utilización de la Red como recurso educativo.

\section{5.- CONCLUSIONES}

Las Tecnologías de la Información y las Comunicaciones (TIC) han tenido una gran influencia a nivel socioeconómico en todos los sectores productivos de los países

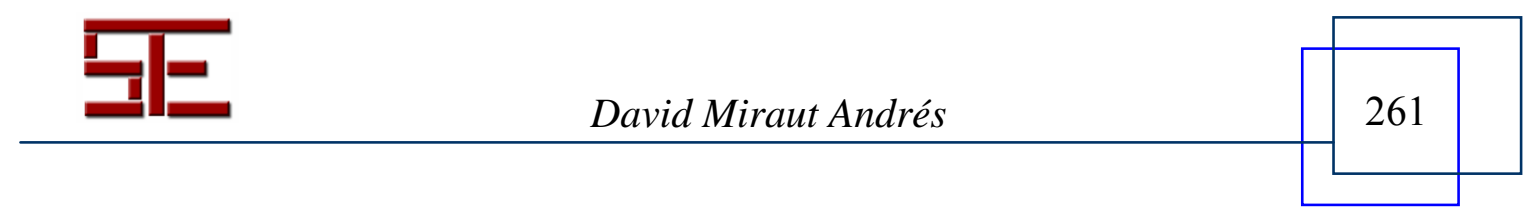




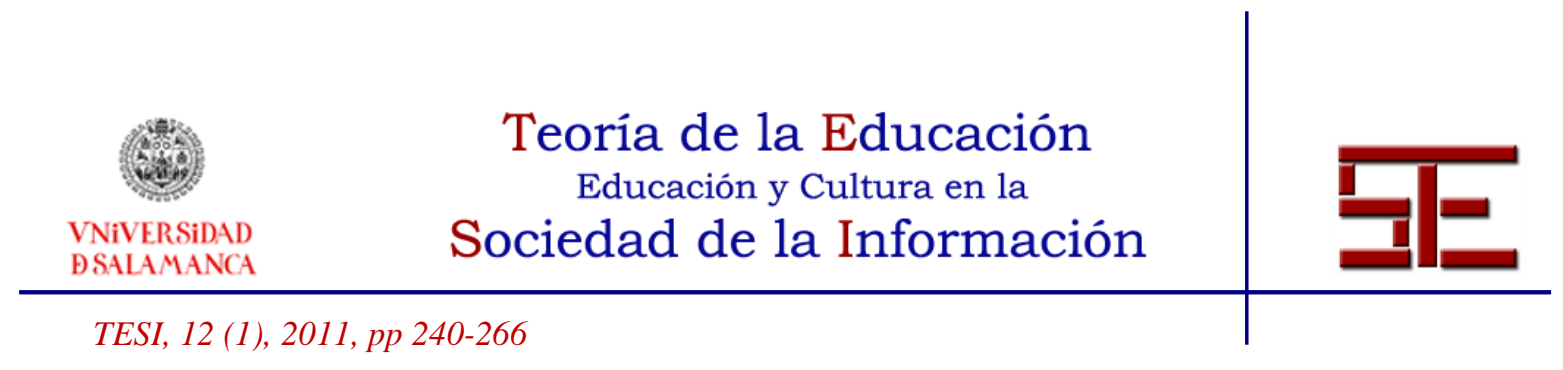

occidentales. Internet se ha convertido en el gran repositorio de conocimientos de la Humanidad - un sueño de generaciones hecho realidad-, sin embargo sólo un porcentaje irrisoriamente bajo de la población que tiene acceso lo aprovecha para mejorar su formación.

Por esta razón, todos los países están haciendo cuantiosas inversiones para formar a sus jóvenes y dotarles de las habilidades que pueden suponer una diferencia competitiva en las industrias del futuro, y en particular en aquellas relacionadas con las TIC. El proyecto OLPC, inicialmente pensado para reducir la brecha digital en los países en vías de desarrollo, ha tenido un impacto inesperado al crear un nuevo mercado que ha facilitado la incorporación de las TIC en la educación de los países industrializados.

La deficiente formación del profesorado en las nuevas tecnologías y la escasez de contenidos adaptados a las necesidades de cada comunidad han supuesto obstáculos difíciles de salvar en la incorporación de las TIC en el día a día de las escuelas y centros de educación secundaria en los países de habla anglófona. El proyecto español Escuela 2.0 ha sabido aprender de las experiencias anteriores, pero sigue estando demasiado enfocado a la creación de infraestructuras. La falta de una conciencia sobre el ecosistema de las soluciones TIC ha obligado a que los profesores se hiciesen cargo de la generación de contenidos, invirtiendo un tiempo que podría haberse dedicado a crear soluciones más innovadoras.

Los resultados del informe PISA han dado una lección de humildad a los sistemas educativos occidentales, demostrando que más medios materiales no suponen un mejor aprovechamiento académico por parte de los alumnos. La sociedad y el ambiente familiar deben alentar a los estudiantes a dar lo mejor de sí mismos. La educación no consiste sólo en adquirir conocimientos, sino también en la formación del carácter, al coincidir, sobretodo la educación secundaria con los años críticos de la adolescencia. La infancia y la adolescencia son épocas en las que se debería incentivar las ganas de crear, imaginar e idear de nuestros jóvenes. Pero, desgraciadamente, nuestro entorno está fomentando una actitud pasiva en ellos, convertidos en meros consumidores de contenidos frente a una pantalla se disipan sus inquietudes por descubrir cómo están hechas las cosas y porqué funcionan. La tecnología les parece magia y dejan de preguntase cómo aprovecharla para hacer aquello que más les gusta de otras formas.

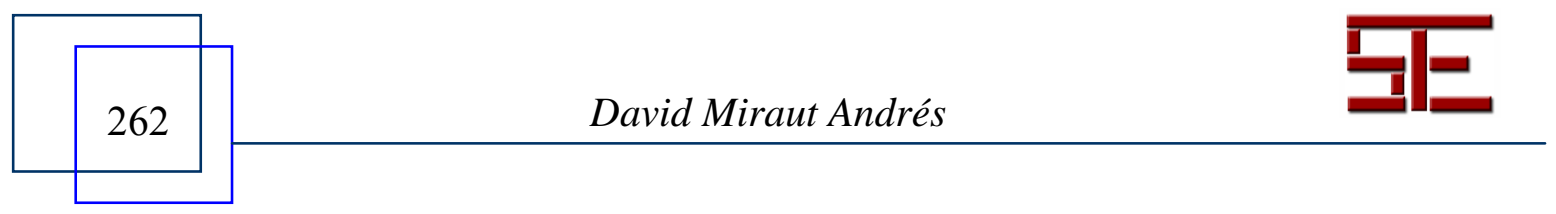




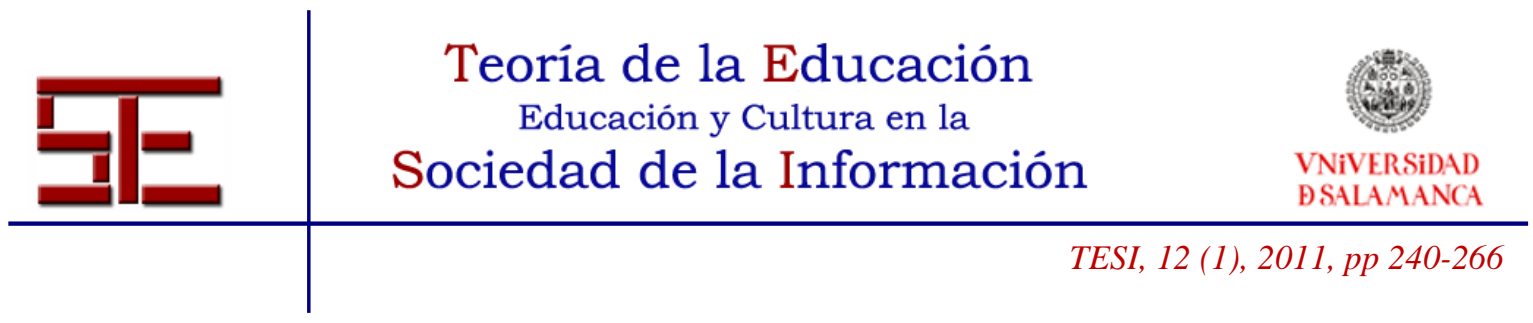

El sueño de Isaac se está haciendo realidad, pero todavía hay un gran salto entre los contenidos asimilables por los niños y los contenidos de calidad pensados para estudiantes universitarios, especialmente en lo relativo a la barrera lingüística que supone todavía el inglés. Está en nuestras manos el crear contenidos atractivos para los jóvenes nativos digitales que despierten su curiosidad y les ayuden a desarrollar la capacidad de aprender a aprender. Los juegos serios se están haciendo cada vez más populares en todos los ámbitos de la formación. En España tenemos 700.000 jóvenes sin estudios menores de 34 años (Llamas, 2010), un nicho de mercado para la formación que puede aprovechar las TIC para animarles a estudiar.

Un aprendizaje que -al igual que el de todos los demás- durará toda la vida en un mundo digital.

\section{6.- BIBLIOGRAFÍA.}

Asimov, I. (1986). Cambio! 71 visiones de futuro. Madrid: Alianza

Central Pacific Railroad Photographic History Museum (1860). The Pacific Telegraph Act. of 1860. Extraído el 20 Diciembre, 2010 de http://cprr.org/Museum/Pacific_Telegraph_Act_1860.html

Carabaña, C. (2010) Llena de educación tu portátil, El País. 20 de Diciembre. Extraído el 20 Diciembre, 2010 de

http://www.elpais.com/articulo/educacion/Llena/educacion/portatil/elpepuedu/2010122 0elpepiedu_2/Tes

Clarke, A.C. (1962). Profiles of the Future; an Inquiry into the Limits of the Possible. New York: Harper \& Row.

Dynarski, M., Agodini, R., Heaviside, S., Novak, T., Carey, N., Campuzan, L., Means, B., Murphy, R., Penuel, W., Javitz, H., Emery, D. y Susse, W. (2007). Effectiveness of Reading and Mathematics Software Products: Findings from the First Student Cohort. Washington: National Center for Education evaluation and Regional Assistance.

Fernandez-Villaverde, J. (2010) Mi sobrina y PISA. Nada es Gratis. Extraído el 20 Diciembre, 2010 de http://www.fedeablogs.net/economia/?p=8117

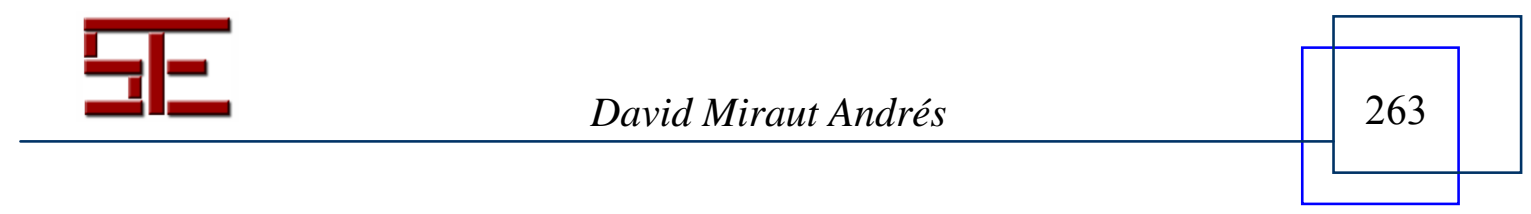




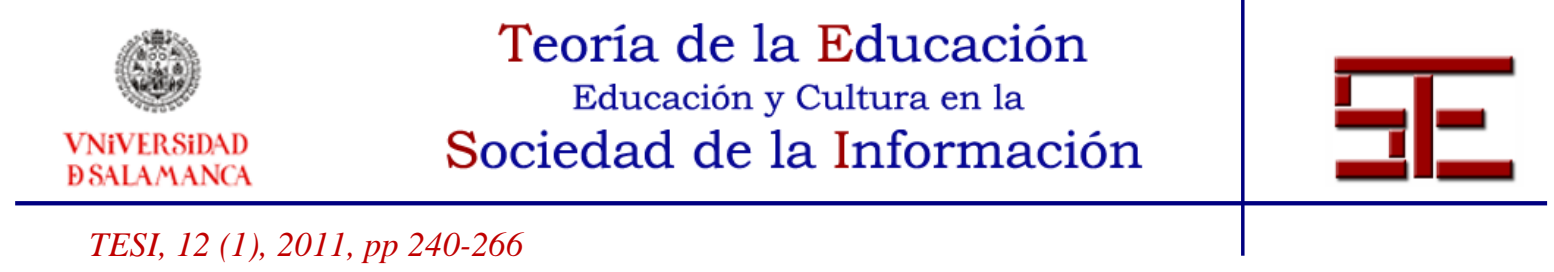

Gordon R.J. (2000). Does the new economy measure up to the great inventions of the past, Journal of Economic Perspectives, 14(4), 49-74 .

Henderson, P. (2008). Computer Science unplugged. Journal of Computing Sciences in Colleges 23(3)

Hourcade, J.P., Beitler, D., Cormenzana, F., y Flores, P. (2008). Early OLPC experiences in a rural Uruguayan School. En Proceedings de CHI 2008 (pp. 25032511) NuevaYork: ACM Press.

Hummel, C. (1971). Education today for the world of tomorrow. Suiza: United Nations Educational

Hu, W, (2007). Seeing no progress, some Schools drop laptops. New York Times. 4 Mayo.

Instituto de Evaluación (2010). PISA 2009. Programa para la Evaluación Internacional de los Alumnos. OCDE INFORME ESPAÑOL. Madrid: Ministerio de Eduación

Kraemer, K.L., Dedrick,J. y Sharma, P. (2009), One Laptop Per Child: Vision vs. Reality, Communications ACM, 52(6)

Llamas, M. (2010). La generación ni-ni: más de 700.000 jóvenes españoles ni estudian ni trabajan. Libertad Digital. 8 de Enero. Extraído el 20 Diciembre, 2010 de http://www.libertaddigital.com/economia/la-generacion-ni-ni-crece-mas-de-700000jovenes-ni-estudian-ni-trabajan-1276380877/

Manuel, K.M. (2009). Google Library Project: Is Digitization for Purposes of Online Indexing Fair Use Under Copyright Law?. CRS Report for Congress. Washington:

Congressional Research Service,Library of Congress

Marcano, B. (2008). Juegos serios y entrenamiento en la sociedad digital. Teoría de la Educación: Educación y Cultura en la Sociedad de la Información, 9(3), 93-107

McKinsey Global Institute (2002). Whatever happened to the new economy?, San Francisco.

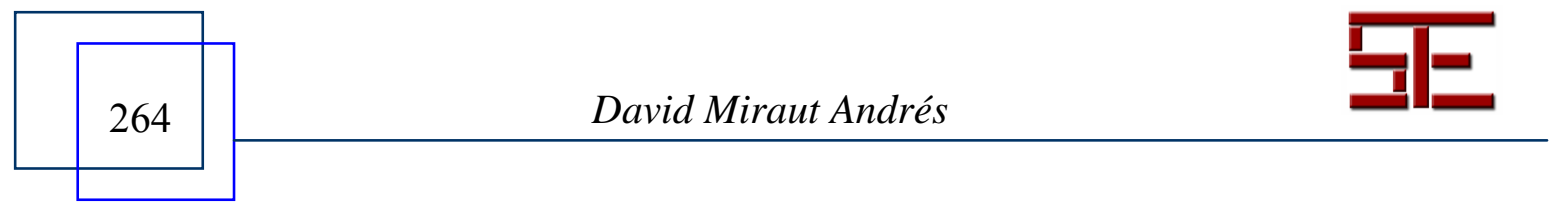




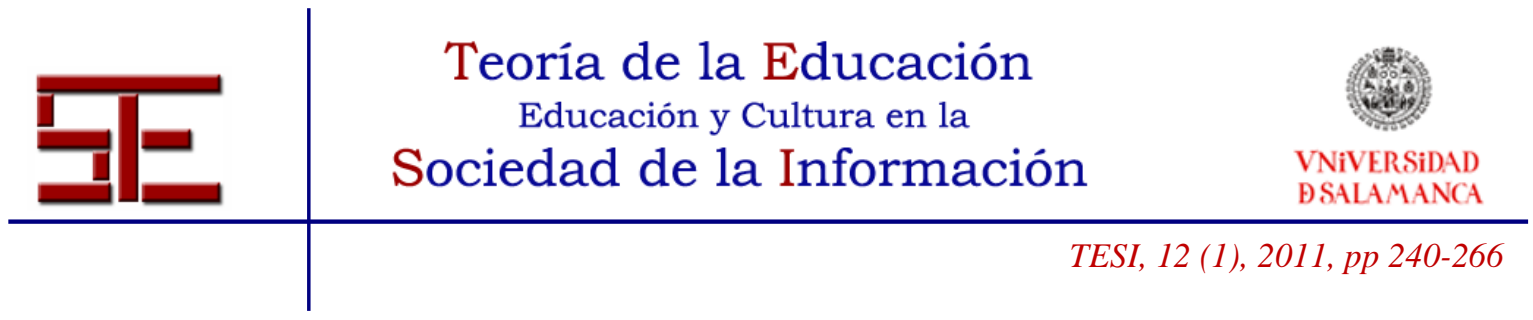

Mervis, J. (2010) Shanghai Students Lead Global Results on PISA. Science. 330(6010), p. 1461

Ministerio de educación (2010). El Gobierno refuerza con cerca de 6 millones de euros el programa Escuela 2.0. Nota de prensa. . Extraído el 20 Diciembre, 2010 de http://www.educacion.es/horizontales/prensa/notas/2010/12/consejo-escuela20.html Miraut, D. Mendoza, A,. Ruiz, S. y Montano, I. (2010) Rebeca a través del espejo. En las Actas de las I Jornadas en Innovación y TIC Educativas (JITICE). Móstoles.

Mollers, B. (1988). Moyers Digital Archive: World of Ideas. Extraído el 20 Diciembre, 2010 de http://www.youtube.com/watch?v=1CwUuU6C4pk

Moumouni A. (1975). The return to national languages and cultures. Prospects, 5(1), 63-70.

Muir, M., (2007), Lessons learned from 1-to-1 laptop initiatives: Reflections on critical components. En Proceedings of the Society for Information Technology and Teacher Education 16th Annual Conference, (pp. 4366-4371) Orlando: AACE,

Pedro, F. (2009). New Millenium Learners in Higher Education: Evidence and Policy Implications. En International Conference on 21st Century Competencies. Bruselas: OECD.

Peña-López I. (2010). From laptops to Competences: Bridging the Digital Divide in Education, Revista de Universidad y Sociedad del Conocimiento, 7(1), 21-32

Perry, T.S. (2007). The laptop crusade. IEEE Spectrum, 44(4), 28-33

Prensky, M. (2001). Digital Natives, Digital Immigrants. On the Horizon, 9(5), 1-6.

RTVE (2009), El programa Escuela 2.0 arranca con 7.100 alumnos de más de 300 aulas de varias comunidades. Extraído el 20 Diciembre, 2010 de http://www.rtve.es/noticias/20090904/programa-escuela-20-arranca-7100-alumnos-mas300-aulas-varias-comunidades/291116.shtml

Sayare, S. (2009). France to Digitize Its Own Literary Works. New York Times. 14 Diciembre.

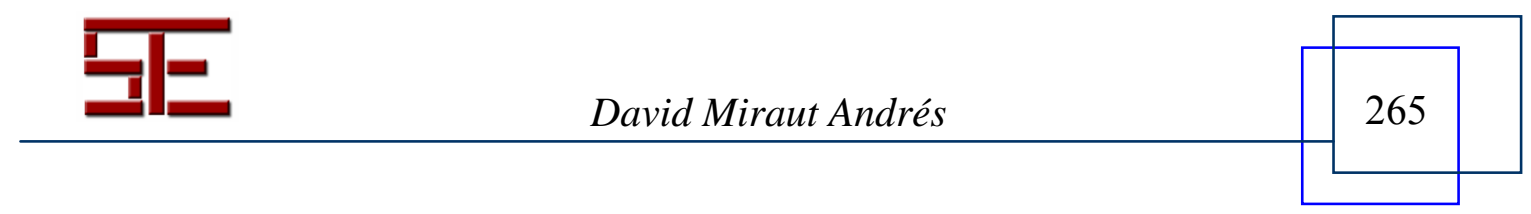




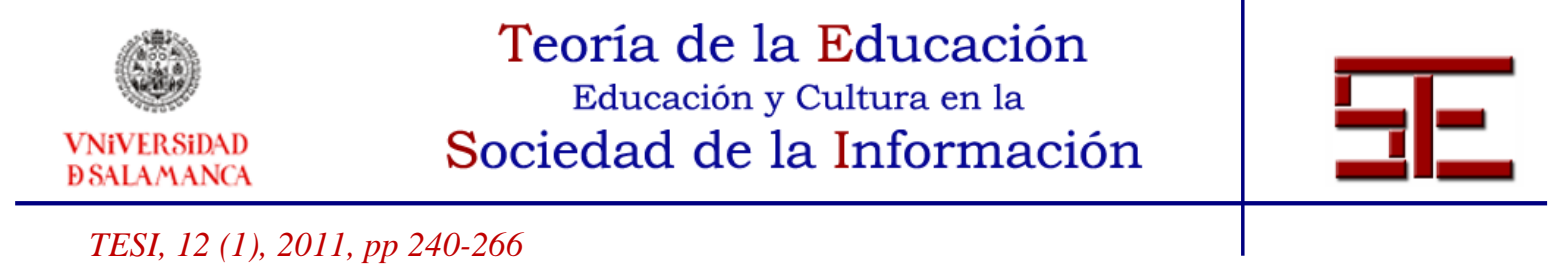

Texas Education Agency, (2009). Evaluation of the Texas Technology Immersion Pilot Final Outcomes for a Four-Year Study (2004-05 to 2007-08). Texas: Texas Center for Educational Research

Van der Sande \& Cia. (2008). Another New OLPC Mission Statement?!. Extraído el 20 Diciembre, 2010 de http://www.olpcnews.com/people/negroponte/new_olpc_mission_statement.html

Verne, J. (1863). Paris en el siglo XX. Edición publicada en el año 2000. Santiago de Chile: Andres Bello.

Vota, W. (2007) OLPC Nepal creates content while Negroponte dismisses it. One Laptop Per Child News. Extraído el 20 Diciembre, 2010 de www.olpcnews.com/countries/nepal/negroponte_curriculum_content.html

Warschauer, M. (2006). Laptops And Literacy: Learning in the Wireless Classroom. Nueva York: Teachers College Press

Wells, H.G. (1937). The Idea of a Permanent World Encyclopaedia. Contribución a la Encyclopédie Française. Extraído el 20 Diciembre, 2010 de https://sherlock.ischool.berkeley.edu/wells/world_brain.html

$\mathrm{Wu}$ (2003). Network Neutrality, Broadband Discrimination. Journal on Telecommunications and High Technology Law, 2(1), 141-176

Zuckerman, E. (2007). Other Roads to Computing for All. IEEE Spectrum, 44(4), 28-33

Para citar el presente artículo puede utilizar la siguiente referencia:

Miraut Andrés, D. (2011). El sueño de Isaac y la transformación de los sistemas educativos en la sociedad de la información, en Hernández Serrano M. J. y Fuentes Agustí, M. (Coords.) La red como recurso de información en educación. Revista Teoría de la Educación: Educación y Cultura en la Sociedad de la Información. Vol. 12, $\mathrm{n}^{\circ}$ 1. Universidad de Salamanca, pp. 240-266 [Fecha de consulta: dd/mm/aaaa]. http://campus.usal.es/ revistas_trabajo/index.php/revistatesi/article/view/7832/7858

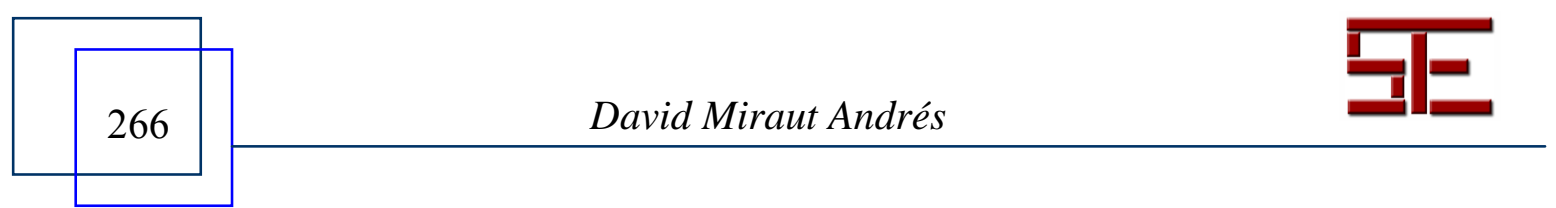

